\title{
Article \\ Systematic Development of a Powder Deposition System for an Open Selective Laser Sintering Machine Using Analytic Hierarchy Process
}

\author{
Foivos Psarommatis ${ }^{1}$ (D) and George-Christopher Vosniakos ${ }^{2, *(D)}$ \\ 1 SIRIUS, Centre for Scalable Data Access, Department of Informatics, University of Oslo, 0316 Oslo, Norway; \\ foivosp@ifi.uio.no \\ 2 Manufacturing Technology Laboratory, School of Mechanical Engineering, National Technical University of \\ Athens, Heroon Polytehniou 9, 15780 Athens, Greece \\ * Correspondence: vosniak@central.ntua.gr
}

Citation: Psarommatis, F.; Vosniakos, G.-C. Systematic Development of a Powder Deposition System for an Open Selective Laser Sintering Machine Using Analytic Hierarchy Process. J. Manuf. Mater. Process. 2022, 6, 22. https://doi.org/10.3390/ jmmp6010022

Academic Editors: Ioannis (John) Giannatsis and Konda Gokuldoss Prashanth

Received: 10 November 2021 Accepted: 2 February 2022

Published: 8 February 2022

Publisher's Note: MDPI stays neutral with regard to jurisdictional claims in published maps and institutional affiliations.

Copyright: (C) 2022 by the authors. Licensee MDPI, Basel, Switzerland. This article is an open access article distributed under the terms and conditions of the Creative Commons Attribution (CC BY) license (https:// creativecommons.org/licenses/by/ $4.0 /)$.

\begin{abstract}
This work reports on the design and manufacture of an efficient system for powder deposition into layers in an open Selective Laser Sintering machine. The system comprises mainly two subsystems, i.e., one that deposits a dose of powder onto the worktable and another that levels the powder upon its deposition. The design was conducted in two phases, namely conceptualization of the system and its detailed design. The conceptualization phase exploited the Analytic Hierarchy Process to evaluate alternative mechanical systems and determine the most suitable one. This was subsequently detail-designed using a CAD software package and then followed by selection of the necessary electronics for imparting and controlling motion of the individual mechanisms comprising the system. As regards manufacturing, custom designed components were obtained by CNC machining and the entire mechanism was assembled on an open Selective Laser Sintering machine. Functionality testing of the system was performed with satisfactory results.
\end{abstract}

Keywords: additive manufacturing; selective laser sintering; analytic hierarchy process; powder deposition; mechatronics

\section{Introduction}

The manufacturing domain is considered to be one of the most critical domains that has significantly impacted economic, social and environmental aspects over the past years [1]. Therefore, it remains extremely important that new products or machine equipment are designed based on structured methodologies and with consideration of multiple criteria in order to contribute to the overall sustainability [2]. Additive Manufacturing (AM) presents one of the many new technologies the Industry 4.0 concept has proposed. Compared with the traditional subtractive manufacturing processes, AM enabled the creation of 3D objects by addition of materials constructed from a computer-based 3D model [3-6]. To this extent, AM offers great opportunities and possibilities for implementing the vision of Industry 4.0 [7]. Selective Laser Sintering (SLS) is one of the leading AM techniques and a recent study showed that this trend will continue into the future [8]. Powder deposition is an important sub-process in SLS affecting the quality of the powder layer and, consequently, process precision and stability [9]. The main requirements for the layer are: uniform thickness and homogeneity. Until now, no universal deposition solution has been produced, that is suitable for all kinds of powder [10]. It is well known that humidity affects the flow rate of powders, owing partly to the formation of liquid bridges [11]. The relative humidity, in which the flow rate of metal and ceramic powders is only marginally influenced, ranges from $30-80 \%$ [12].

The current paper proposes a structured methodology based on the Analytical Hierarchy Process (AHP) for evaluating alternative designs and selecting the best among the 
available based on multiple criteria. AM and specifically SLS Powder Deposition System (PDS) will be used as an example of the utilization of the proposed methodology. SLS powder deposition is selected as an example since the technical literature lacks detail on how powder deposition is performed, referring to it mostly in an abstract way and bypassing design details.

The structure of the paper is as follows. In Section 2 some key findings are presented regarding other methodologies for evaluating alternative designs of different domains in addition to an analysis of the different technologies that are known concerning the PDS problem. Section 3 briefly presents the Analytical Hierarchy Process (AHP) for comparing alternative PDS concepts based on specific evaluation criteria. AHP is applied in Section 4 resulting using the most suitable alternative concept. Detailed design of this concept is presented in Section 5 followed by manufacturing details and testing. Section 6 outlines the conclusions of this study.

\section{State of the Art}

\subsection{Design Proceedures in the Manufacturing Domain}

In the literature, there are numerous methods employed for designing products, machinery and manufacturing systems. Some of the most relevant methods irrespective of the addressed subdomain are indicatively presented next. A parametric lifecycle assessment was proposed to optimize the eco-friendliness of alternative designs. The proposed method is applicable to a high variety of sub-domains in manufacturing. The results from two case studies revealed that the proposed parametric lifecycle assessment was capable of identifying the optimum design based on multiple criteria and constraints [13]. A mathematical programming approach was proposed for optimizing the design of layered cellular manufacturing systems towards a minimization of the number of cells. The results obtained when comparing with existing heuristics from the literature were mixed and there was no dominant solution [14]. A discrete event simulation engine was proposed using different metaheuristic and intelligent methods for identifying the optimum manufacturing network design aimed at achieving mass customization. Numerous alternative designs were automatically generated and evaluated using multiple conflicting criteria. In some cases, significant computation time was required for extended simulations $[15,16]$. The combination of discrete event simulation and a digital twin model were used for the design of a manufacturing system to achieve Zero Defect Manufacturing (ZDM) [17,18]. The digital twin model was created using a discrete event simulation engine and then the specific industrial case was analyzed and mapped according to the ZDM principles. Using the produced mapping, the alternative design options could be compared and the best one selected [19]. In the turbomachinery design domain, a 1D design method was proposed which details the integration between the cycle conceptual design and components preliminary design. The differing designs were evaluated and the results were validated both numerically and experimentally [20]. The analytical hierarchy process (AHP) was used for selection of material handling equipment [21]. Moreover, it was used in combination with Pugh Matrix methods for the comparison of concept designs of reconfigurable manufacturing systems, but very few details were provided [22].

\subsection{Powder Deposition Methods}

The powder deposition methods in SLS machines have been categorized in the literature according to the principle that they utilize, namely: mechanical, electrostatic, vibratory and miscellaneous methods.

\subsubsection{Mechanical Methods}

This is the most commonly employed method, in which the powder is spread using mechanical means. The PDS reported in [23] uses a combination of a slot feeder and a counter rolling cylinder. The powder deposition starts with the piston supporting the powder bed which lowers at a depth which is slightly larger than the required layer 
thickness. Next, the slot-feed mechanism adds a loose layer of powder over the bed surface. In the third stage, the piston rises again over a fraction of the layer thickness, after which the cylinder rolls over the powder and performs compaction. The resulting compaction should be comparable to tapping [24]. In another study, a slot feeder was used for powder layering in which the powder material was fed into the machine intermittently via two storage tanks which were located at the side of the machine containing new and recycled powder, respectively [25].

The combination of a doctor blade and a counter rotating roller led to promising results regarding density [26], especially with a roller diameter of $22 \mathrm{~mm}$ for the particular powder type used. Powder was noted to sometimes adhere to the forward rotating roller, thus leaving craters in the newly formed layer. Furthermore, the level of compression is influenced by the amount of loose powder in front of the roller.

Another alternative concerns the use of a feeder bin. The powder is stored in a bin which is located adjacent to the building platform. First, the feed bin is raised by the thickness of a layer, then a blade or a roller spreads the powder on the building surface. Spreading and compaction of the powder are performed simultaneously [27-29]. In research conducted by [28], a manufacturing plateau, a powder feeding plateau and a stainless steel knife as layering device were employed, allowing the spread layer thickness to reach between $30-80 \mu \mathrm{m}$ with $\pm 5 \mu \mathrm{m}$ accuracy. Furthermore, the set up utilized a heating system composed of six high power infra-red (IR) radiant lights operating in the $0.7-2 \mu \mathrm{m}$ wavelength range in order to heat up the PA12 powder to $373^{\circ} \mathrm{K}$ and PEEK powder in the range $373-473^{\circ} \mathrm{K}$ for about $10 \mathrm{~s}$.

\subsubsection{Electrostatic Methods}

Electrostatic powder coating consists of three stages, namely: (a) coating powder is fluidized in a reservoir by blowing air from a perforated base (b) the fluidized powder is blown along a feed pipe to a dispensing and charging gun (c) depending on the type of gun, the third stage varies. For triboelectric guns, fluidized powder is blown vigorously through the barrel maximizing triboelectric charging and then blown towards the workpiece to be coated. For the more common corona gun, the gun charges powder particles by ensuring that they pass through a corona discharge in the gun exit.

The simplest gun consists of a cylindrical barrel at the end of which one or more sharply pointed electrodes are placed and maintained at a high negative potential of 60-100 kV. The intense voltage gradient in the vicinity of the electrode tips sets up a stable corona discharge through which emerging powder particles pass and are charged by negative ion attachment. Triboelectric and corona guns both produce a charged powder cloud in the transport region resulting in a space-charge electric field directed towards the earthed workpiece and terminating upon it. In the corona gun, there is an additional electric field between the gun and the workpiece due to the high potential of the corona electrode [30].

According to the electrophotographic method, the powder particles are lifted via electrostatic force and deposited on a charged surface. Powder can be picked up using a photo-conducting belt or a drum. The photoconductor drum is charged using a charging roller, which is a contact charging device [31]. The belt is specially coated on one side with a material that becomes conductive upon absorbing light. The belt is cleaned by a cleaner and charged by a charging device. An image projector then discharges the belt selectively by projecting light onto the belt ensuring only the desired area remains charged. Then, when the belt contacts the image developer, powder particles become stuck on the charged region. The developer not only acts as powder container but also charges and transports the powder to the photoconductor. However, positioning subsequent layers precisely over previous layers requires a robust control system [32,33].

\subsubsection{Vibratory Methods}

Vibration has long been used to improve packing efficiency of powder prior to compaction processes [34]. Pertinent methods include low frequency, motor- or solenoid-driven, 
vibratory and shaker feeders. Vibratory flows use vertical down-pipes controlled by either longitudinal or transverse acoustic or, more recently, ultrasonic vibration [35]. Models have been devised regarding time-dependence of increase in apparent density as a result of both individual particle rearrangement and relaxation of particle clusters [36].

Vibratory feeders are a common alternative and experimental setups are reported for the on and off switching of powder flow, and for controlling the rate of flow acting both as a proportional valve and an on/off valve. Hall flow meters fitted with axial and transverse vibration providing accelerations up to $2.7 \mathrm{G}$ and having 2.5 or $5 \mathrm{~mm}$ orifices have been reported $[37,38]$. A micro-feeding method has been also employed based on vibrations of a vertical capillary tube attached to a hopper by an electric motor [39]. Furthermore, a critical frequency in the region of several hundred $\mathrm{Hz}$ exists below which powder flow stops; this turns out to be inversely proportional to the amplitude and to the capillary diameter. Flow rate increases with frequency reaching an upper limit.

Ultrasound in the range of $20 \mathrm{kHz}$ can be typically transmitted from a sonicator probe to a capillary tube through water also allowing for miniaturization [40-43]. A tube diameter in the range $0.6-1.3 \mathrm{~mm}$ results in flow rate of a few $\mathrm{mgr} / \mathrm{sec}$. Flow rate is extremely sensitive to capillary diameter and increases with power delivered to the ultrasonic probe for capillaries less than $0.81 \mathrm{~mm}$ in diameter but decreases at higher power levels for capillaries of $1.04 \mathrm{~mm}$ in diameter. It was speculated that a vibrating layer of powder close to the wall acts as a lubricant. Ultrasonic control of flow rate through a valve with an annular gap at the base of a vertical tube has also been described [44-46]. The base is connected by a central rod to the actuator. Flow rate correlates almost linearly to vibrational velocity. Ultrasonic feeding mechanisms have been refined to provide flow rates down to $10 \mu \mathrm{g} / \mathrm{sec}$ using capillary diameters of $125 \mu \mathrm{m}$ and $50 \mu \mathrm{m}$ for powders of about $3 \mu \mathrm{m}$ [47]. Specially designed valves consisting of capillary tubes subjected to lateral acoustic vibration have also been used [48]. Flow rate is controlled by amplitude and frequency in the range 25-300 Am and 50-300 Hz, respectively.

\subsubsection{Other Methods}

Such methods are only briefly presented since they are not compatible with the existing SLS machine, mostly due to a lack of space. Yet, some of their characteristics may be used.

In a typical application of the aerosol method, titanium dioxide powder films were prepared from a titanium oxide acetylacetonate liquid solution, optimally of concentration $0.5 \mathrm{M}$, that was briefly exposed to an electrostatic atomizer, sprayed onto heated aluminum substrates to optimally $350{ }^{\circ} \mathrm{C}$ and densified by a laser system [49]. The method can produce ideal layers for selective laser densification of desired ceramic patterns.

Coaxial powder delivery involves a powder feeder, powder nozzle and shield gas circuit. Complex cooling water channels are designed around the powder nozzle to cool the system [50]. The system introduced in research by [51] has shown stable performance, uniform powder flux, high cooling efficiency and long useful life.

\subsection{Research Gaps}

Based on the literature review performed, several research gaps were identified and were the drivers for the current research work. First and foremost, there is no clear methodology detailing how alternative concept designs can be compared. Only AHP displayed promising signs that it could cope with that challenge successfully. Second, to the authors' best knowledge there is no research work that uses the AHP method for designing a mechanical assembly. Third, in the Additive Manufacturing domain, there is no study that presents a detailed design of a powder deposition mechanism on SLS machines. Therefore, the purpose of the current paper is two-fold, namely, to suggest a structured, easy to use and quick methodology for properly designing an intricate high-precision mechanical assembly and at the same time to shed light on the powder deposition mechanism design. 


\section{Methodology}

In Section 2.2 various methods of powder deposition were introduced with the aim of harnessing this information in generating concept designs for the powder deposition mechanism [52]. According to this review, mechanical deposition takes advantage over the other types as it is much more straightforward to adopt within an open machine prototype that is to be designed and manufactured in-house.

The main requirement of the mechanism is the minimum thickness of the powder layer to be deposited which is set to $20 \mu \mathrm{m}$. The alternative design concepts are to be evaluated according to a set of criteria following AHP [53]. The prevailing design should then be detail designed, manufactured, installed and tested. Figure 1 illustrates at an abstract level the steps followed during this study. The proposed evaluation process differs from the traditional AHP implementation. In order to reduce the subjectivity of the AHP method when comparing different concept designs, a two layer AHP evaluation process is proposed [54].

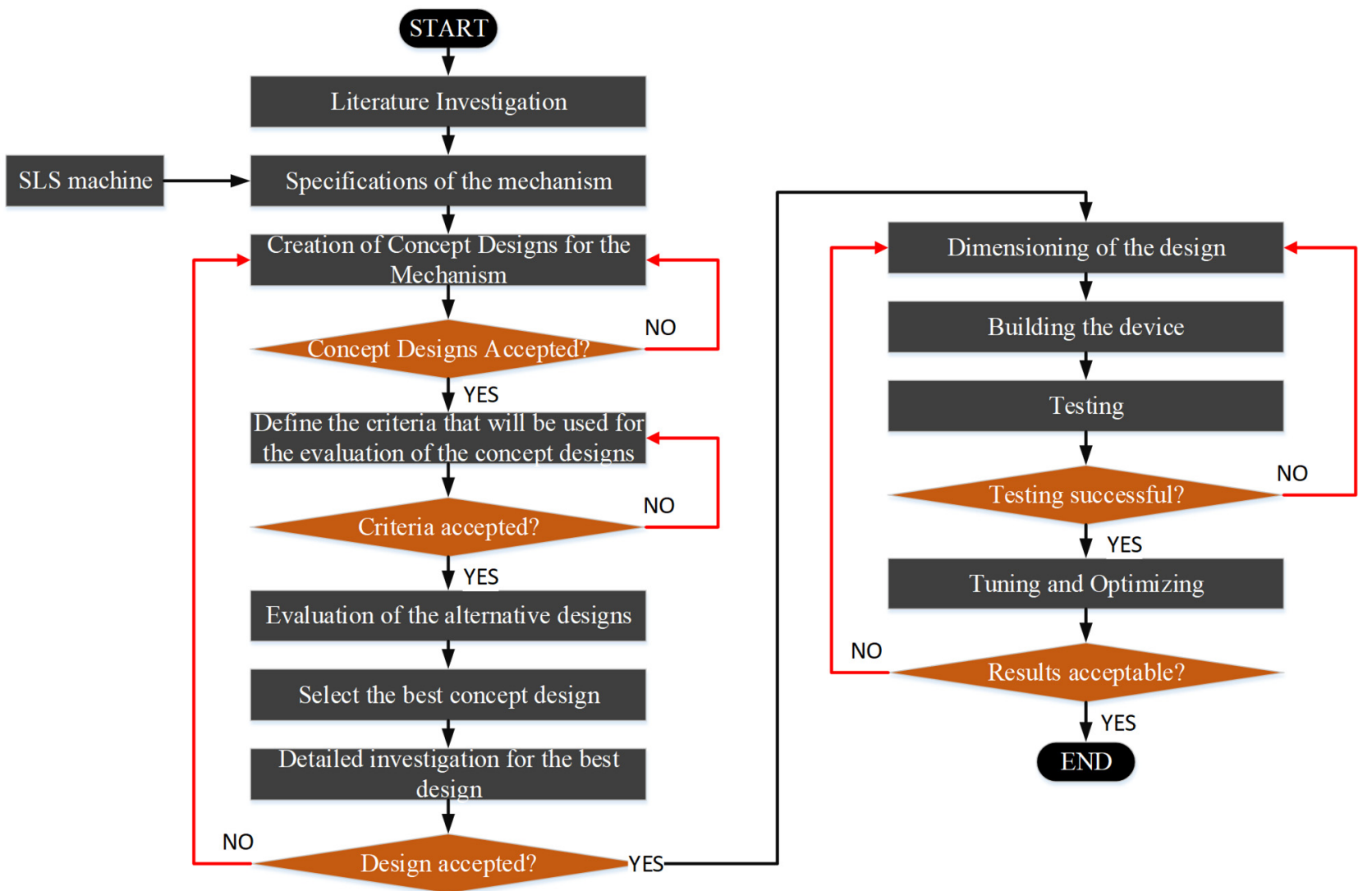

Figure 1. Methodology flow chart.

\subsection{Analytic Hierarchy Process (AHP)}

AHP is a multi-criteria decision-making method originally developed by Saaty [55]. It has attracted the interest of many researchers mainly due to its elegant mathematical properties and the fact that the required input data is rather easy to obtain. AHP uses a multi-level hierarchical structure of objectives, criteria, sub-criteria, and alternatives. The pertinent data is derived by using a set of pairwise comparisons. These comparisons lead to obtaining the weights of importance of the decision criteria, and the relative performance measures of the alternatives regarding each individual decision criterion. At this point it should be noted that the pairwise comparisons and the criterial values assignment have by definition a certain subjectivity, meaning that different people might assign different values to each criterion. However, AHP contains a mechanism for checking consistency of the tables for the pairwise comparisons which counterbalances to a considerable extent 
the subjectivity of the values used. If tables are consistent, then the results can be considered as objective rather than subjective. Furthermore, developing a detailed model that would objectively describe different aspects of each product would require a significant amount of time, effort and resources which the manufacturing industry can clearly not afford.

If the comparisons are not perfectly consistent, a mechanism for improving consistency is provided. The decision making procedure starts with the creation of the "judgment" matrices. A problem has as many judgment matrices as the number of criteria plus a judgment matrix with all the criteria, see Table 1 . The number of alternatives is $M$ and the number of criteria is $N$. The alternatives and the criteria are compared based on the scale presented in Table 2.

Table 1. Judgment matrices with calculated priority vectors.

\begin{tabular}{|c|c|c|c|c|c|c|c|c|c|c|c|}
\hline \multicolumn{5}{|c|}{ Alternative Judgment Matrices } & \multirow[t]{2}{*}{$\begin{array}{l}\text { Priority } \\
\text { Vector }\end{array}$} & & \multicolumn{4}{|c|}{ Criteria Judgment Matrix } & \multirow[t]{2}{*}{$\begin{array}{c}\text { Priority } \\
\text { Vector }\end{array}$} \\
\hline $\mathrm{Cr}_{\mathrm{N}}$ & $\mathrm{Al}_{1}$ & $\mathbf{A l}_{2}$ & $\ldots$ & $\mathrm{Al}_{\mathbf{M}}$ & & & $\mathrm{Cr}_{1}$ & $\mathrm{Cr}_{2}$ & $\ldots$ & $\mathrm{Cr}_{\mathrm{N}}$ & \\
\hline $\mathrm{Al}_{1}$ & 1 & $a_{21}$ & $\ldots$ & $\mathrm{a}_{\mathrm{M} 1}$ & $P V_{1 N}$ & $\mathrm{Cr}_{1}$ & 1 & $c_{21}$ & $\ldots$ & $\mathrm{c}_{\mathrm{N} 1}$ & $\mathrm{PVCr}_{1}$ \\
\hline $\mathrm{Al}_{2}$ & $1 / a_{21}$ & 1 & $\ldots$ & $\mathrm{a}_{\mathrm{M} 2}$ & $\mathrm{PV}_{2 \mathrm{~N}}$ & $\mathrm{Cr}_{2}$ & $1 / c_{21}$ & 1 & $\ldots$ & $\mathrm{c}_{\mathrm{N} 2}$ & $\mathrm{PVCr}_{2}$ \\
\hline$\vdots$ & $\vdots$ & $\vdots$ & 1 & $\vdots$ & $\vdots$ & $\vdots$ & $\vdots$ & $\vdots$ & 1 & $\vdots$ & $\vdots$ \\
\hline $\mathrm{Al}_{\mathbf{M}}$ & $1 / \mathrm{a}_{\mathrm{M} 1}$ & $1 / \mathrm{a}_{\mathrm{M} 2}$ & $\ldots$ & 1 & $\mathbf{P V}_{\mathrm{MN}}$ & $\mathrm{Cr}_{\mathrm{N}}$ & $1 / c_{N 1}$ & $1 / c_{\mathrm{N} 2}$ & $\ldots$ & 1 & $\mathrm{PVCr}_{\mathrm{N}}$ \\
\hline
\end{tabular}

Table 2. Scale of Relative Importance [53].

\begin{tabular}{cc}
\hline Intensity of Importance & Definition \\
\hline 1 & Equal importance \\
\hline 3 & Weak importance of one over another \\
\hline 5 & Essential or strong importance \\
\hline 7 & Demonstrated importance \\
\hline 9 & Absolute importance \\
\hline $2,4,6,8$ & Intermediate values between two adjacent judgments
\end{tabular}

After all the judgment matrices are formed the principal eigenvectors, i.e., the ones with maximum eigenvalue $\lambda_{\max }$, have to be calculated for each matrix and then normalized by the formulae shown in Table 3. The normalized principal eigenvector represents the priority vector for each judgment matrix and is used to form the entries of the decision matrix.

Table 3. Main notions and corresponding equations in AHP.

\begin{tabular}{cccc}
\hline $\begin{array}{c}\text { Principal Eigenvector } \boldsymbol{i} \\
\text { (for } \boldsymbol{i = 1 , 2 , \ldots ,} \boldsymbol{M}+\mathbf{1})\end{array}$ & $\begin{array}{c}\text { Normalized Principal } \\
\text { Eigenvector }\end{array}$ & $\begin{array}{c}\text { Consistency } \\
(\boldsymbol{C I})\end{array}$ & $\begin{array}{c}\text { Consistency Ratio } \\
\text { (CR) }\end{array}$ \\
\hline$\left[\begin{array}{ccc}V_{11} & \cdots & V_{1 M} \\
\vdots & \ddots & \vdots \\
V_{M 1} & \cdots & V_{M M}\end{array}\right]$ & {$\left[\begin{array}{ccc}\frac{V_{11}}{\sum_{i=0}^{M} V_{i 1}} & \cdots & \frac{V_{1 M}}{\sum_{i=0}^{M} V_{1 i}} \\
\vdots & \ddots & \vdots \\
\frac{V_{M 1}}{\sum_{i=0}^{M} V_{i 1}} & \cdots & \frac{V_{M M}}{\sum_{i=0}^{M} V_{1 i}}\end{array}\right]$} & $C I=\frac{\lambda_{\max }-n}{n-1}$ & $C R=\frac{C I}{R C I}$ \\
\hline
\end{tabular}

The next step is the calculation of the consistency of each of the judgment matrices. First the Consistency $(C I)$ index has to be calculated, see Table 3, where $n$ is the order of the matrix. Then the Consistency ratio $(C R)$ can be calculated, see Table 3 , a value less than $10 \%$ pointing to adequate consistency [53]. Note that RCI (Random Consistency Index) is based on Table 4 . 
Table 4. Random consistency index values [55].

\begin{tabular}{|c|c|c|c|c|c|c|c|c|c|c|c|c|c|c|c|}
\hline$n$ & 1 & 2 & 3 & 4 & 5 & 6 & 7 & 8 & 9 & 10 & 11 & 12 & 13 & 14 & 15 \\
\hline RCI & 0.00 & 0.00 & 0.58 & 0.90 & 1.12 & 1.24 & 1.32 & 1.41 & 1.45 & 1.49 & 1.51 & 1.48 & 1.56 & 1.57 & 1.59 \\
\hline
\end{tabular}

The final step is the formation of the decision matrix, see Table 5, which consists of the priority vectors of the alternative judgement matrices; note the priority vector of the criteria judgment matrix on the first line. Final Priority can be calculated from Equation (1). The alternative with the highest "Final Priority" is the predominant solution for the problem.

$$
F P_{i}=\sum_{j=1}^{N} P V_{j i} \times P V C r_{j}
$$

Table 5. Decision Matrix.

\begin{tabular}{|c|c|c|c|c|c|}
\hline \multicolumn{5}{|c|}{ Alternative Judgment Matrices } & \multirow[t]{2}{*}{ Final Priority } \\
\hline & $\mathrm{Cr}_{1}$ & $\mathrm{Cr}_{2}$ & $\ldots$ & $\mathrm{Cr}_{\mathrm{N}}$ & \\
\hline & $\mathrm{PVCr}_{1}$ & $\mathrm{PVCr}_{2}$ & & $\mathrm{PVCr}_{\mathbf{N}}$ & \\
\hline $\mathrm{Al}_{1}$ & $\mathrm{PV}_{11}$ & $\mathrm{PV}_{21}$ & $\ldots$ & $\mathrm{PV}_{1 \mathrm{~N}}$ & $\mathbf{F P}_{1}$ \\
\hline $\mathrm{Al}_{2}$ & $\mathrm{PV}_{12}$ & $\mathrm{PV}_{22}$ & $\ldots$ & $\mathrm{PV}_{2 \mathrm{~N}}$ & $\mathbf{F P}_{2}$ \\
\hline$\vdots$ & $\vdots$ & $\vdots$ & $\vdots$ & $\vdots$ & $\vdots$ \\
\hline $\mathrm{Al}_{\mathbf{M}}$ & $\mathrm{PV}_{1 \mathrm{M}}$ & $\mathrm{PV}_{2 \mathrm{M}}$ & $\ldots$ & $\mathrm{PV}_{\mathrm{MN}}$ & $\mathbf{F P}_{\mathbf{M}}$ \\
\hline
\end{tabular}

\subsection{Evaluation Criteria}

The evaluation process of the alternative concept designs is performed in two phases, as shown in Figure 2. First, the alternative concept designs have to be grouped into subsystems. Second, for each sub-system the AHP method is applied in order to obtain the best for each sub-system [53]. This evaluation is performed based on the 1st set of criteria; the revealed alternatives are then evaluated based on the 2nd set of criteria. The two sets of criteria are shown in Table 6.

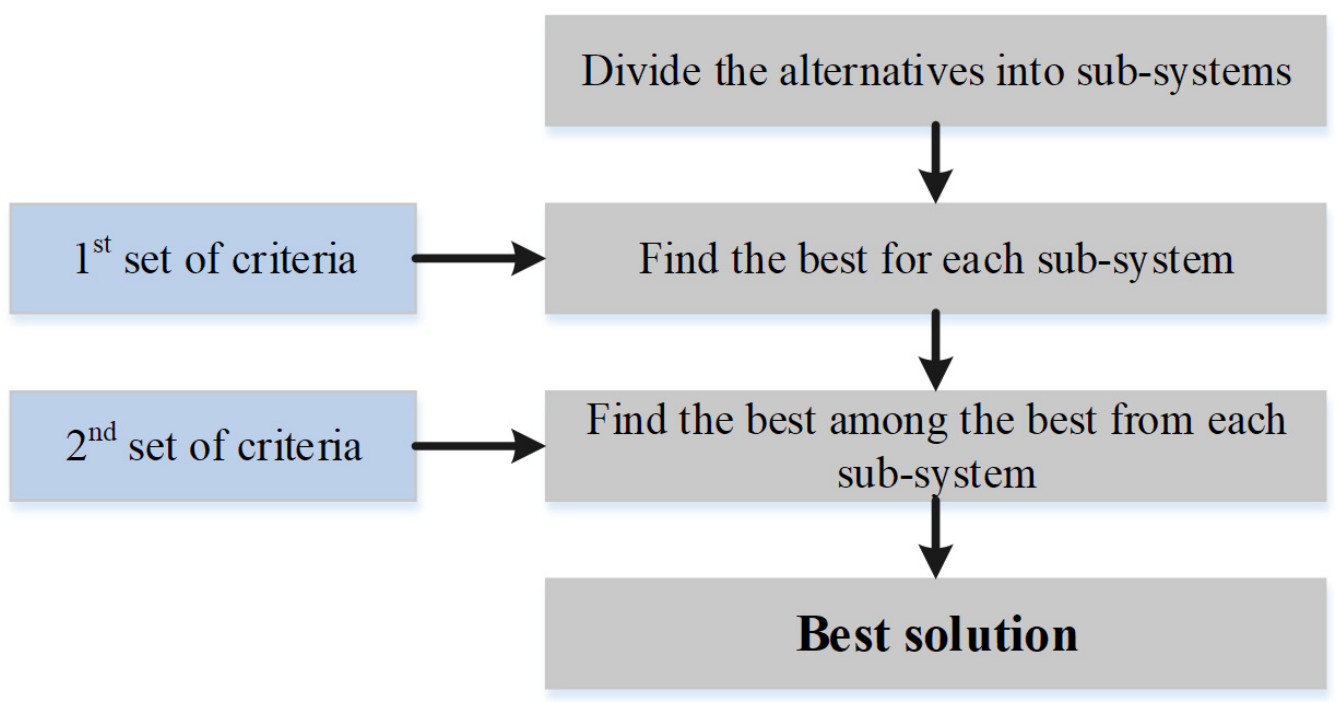

Figure 2. Two-phase decision making. 
Table 6. Evaluation criteria.

\begin{tabular}{|c|c|c|c|}
\hline 1st & 2nd & Criteria & Description \\
\hline $\mathrm{Cr}_{11}$ & - & Process cycle time & $\begin{array}{l}\text { The estimated cycle time for the deposition of } \\
\text { a powder layer. }\end{array}$ \\
\hline $\mathrm{Cr}_{12}$ & - & Weight on the roller & $\begin{array}{l}\text { The estimated weight on the roller, which can } \\
\text { affect the surface quality. }\end{array}$ \\
\hline $\mathrm{Cr}_{13}$ & $\mathrm{Cr}_{23}$ & Cost & $\begin{array}{l}\text { The estimated cost for the fabrication of } \\
\text { the mechanism. }\end{array}$ \\
\hline $\mathrm{Cr}_{14}$ & $\mathrm{Cr}_{24}$ & Manufacturability & $\begin{array}{l}\text { The easiness for manufacturing for } \\
\text { the mechanism. }\end{array}$ \\
\hline $\mathrm{Cr}_{15}$ & $\mathrm{Cr}_{25}$ & Complexity & The estimated complexity of the mechanism. \\
\hline $\mathrm{Cr}_{16}$ & $\mathrm{Cr}_{28}$ & Standalone possibility & $\begin{array}{l}\text { Need for peripheral devices (during the powder } \\
\text { deposition procedure). }\end{array}$ \\
\hline- & $\mathrm{Cr}_{21}$ & Surface quality & $\begin{array}{l}\text { The estimated surface quality of the } \\
\text { powder layer. }\end{array}$ \\
\hline- & $\mathrm{Cr}_{22}$ & Experimental interest & The interest for experimentation. \\
\hline- & $\mathrm{Cr}_{26}$ & Adaptability & $\begin{array}{l}\text { How easy the mechanism can be adapted to the } \\
\text { existing SLS machine. }\end{array}$ \\
\hline- & $\mathrm{Cr}_{27}$ & Geometric constraints & $\begin{array}{l}\text { Number and type of geometric constraints to } \\
\text { consider in mechanism design. }\end{array}$ \\
\hline
\end{tabular}

\section{PDS Concept Development}

\subsection{Generation and Analysis of Alternatives}

The mechanism of loose powder will dispense the powder evenly onto the working area. There are two types of concept designs, namely non-hybrid and hybrid. Furthermore, the designs are categorized based on the method that they utilize for powder depositing, i.e., using vibrations, a slot feeder, a custom-made dosing mechanism, a flat belt plus feed bin mechanism. Due to the importance of this mechanism, several alternative designs are to be investigated. The AHP method will be applied using the first set of criteria in order to acquire the "local" best. The final decision will be made using the second set of criteria as described in Section 3.

Figure 3 presents the alternative concept designs that use only the roller for compaction and a mechanism that dispenses loose powder for the roller to compact. The name of each alternative concept design has been coded as follows: start with "NH" denotes non-hybrid design whereas "HP" denotes hybrid.

The vibratory method utilizes either horizontal or vertical vibration in order to create a flow of the powder inside the powder container. The NHPD11 concept design consists of a roller at one of the two sides of which a small powder container is mounted that is able to vibrate and dispense the powder which the roller compresses almost concurrently. With this configuration, each time a new layer is needed the roller has to deposit the corresponding material and move back to where it started, thus wasting a considerable amount of time. For this reason, an NHPD12 design is proposed, consisting of two powder containers, one for each side of the roller. In this way, deposition time is reduced but another problem arises, i.e., the two powder containers have to vibrate independently and, more importantly, when one is depositing the other has to be totally closed. This is because dropping loose powder from the latter after the roller had compacted the current powder layer would be detrimental to the quality of the final product. This is quite difficult to achieve since both containers are mounted on the same surface, rendering it almost impossible to decouple their vibration. The NHPD13 design solves these problems associated with both NHPD11 and NHPD12 via the addition of a second roller to the system. As a final note, the vibratory method can be very accurate, but it is extremely difficult to theoretically calculate the exact conditions for an exact amount of powder to be deposited in a given period of time. 


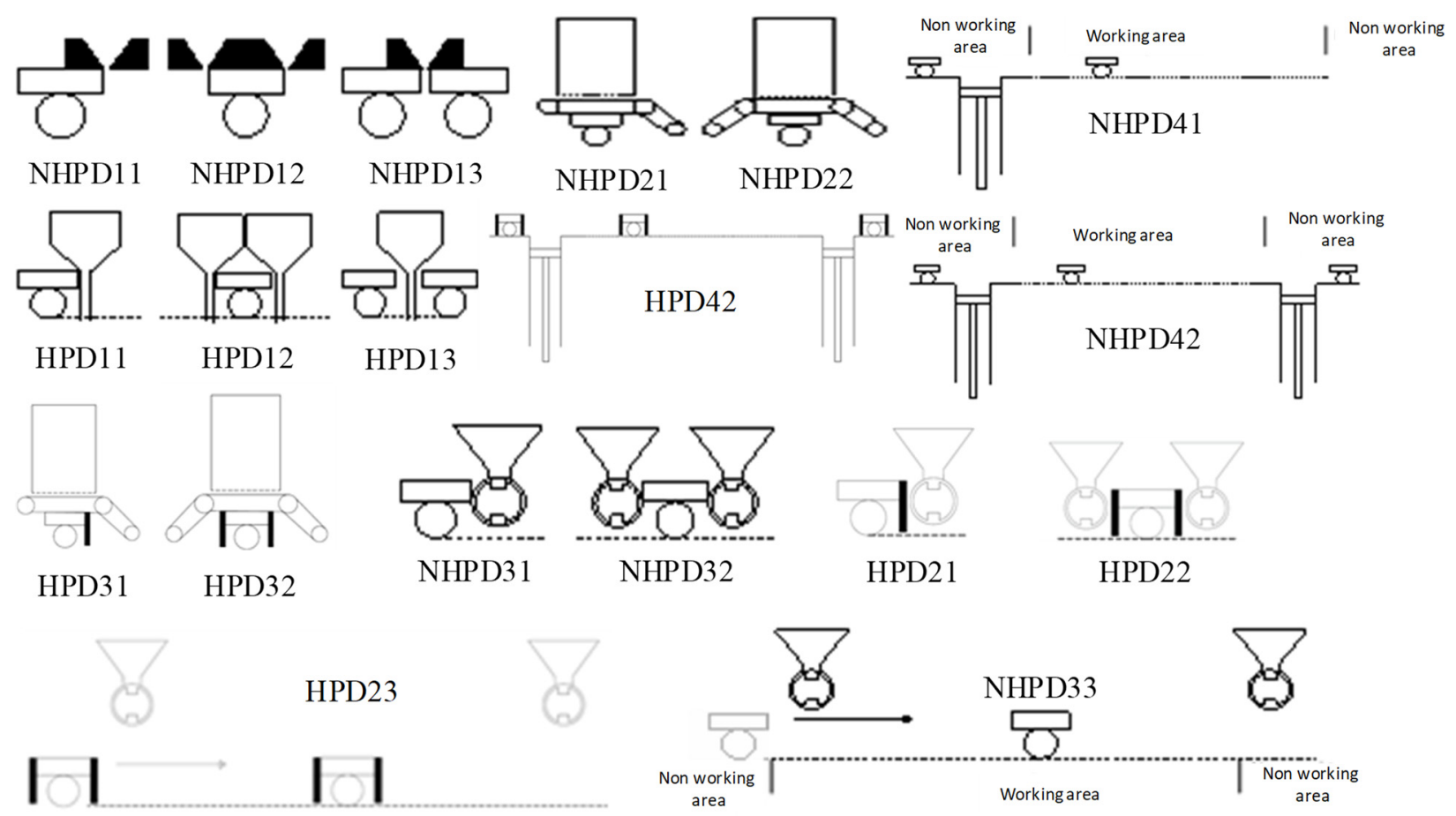

Figure 3. Powder deposition alternative design concept sketches.

Proposed flat belt based concept designs utilize the same principles as the slot feeder, which will be presented later, i.e., the force of gravity and friction between the powder particles and the belt. In design NHPD21, the belt will be able to move in only one direction, therefore, powder deposition will be performed in only one direction in contrast with design NHPD22, which can deposit powder in both directions. However, if the belt is moving too fast there may be a lot of powder floating in the air which can cause surface quality problems during the sintering stage as well as jeopardizing smooth operation of moving parts of the machine by sitting on them leading to abnormal cleaning and maintenance requirements. Moreover, in design NHPD22 if particles of powder have become stuck on the belt, they may drop onto the compacted area resulting in poor surface quality. Furthermore, it is difficult to seal the belt at both sides to prevent it from dropping undesired loose powder on the machine.

The custom-made dosing mechanism is proposed due to its precision, repeatability and ease of assembling. It consists of a rotating cylinder with a number of slots of predetermined depth, which, when rotating, takes powder from the container and drops it in front of the roller. Design NHPD31 can deposit powder only in one direction, consuming a large amount of time. For this reason, in design NHPD32 a dosing mechanism is placed at both sides of the rollers. Design NHPD33 is approximately the same as NHPD32, the main difference being that the dosing mechanisms are stationary at the end of the working space on both sides. This is easier to implement than NHPD32 mostly due to a lack of space above the roller. Furthermore, with NHPD33 no further mechanism is needed to fill the dosing mechanisms with powder.

The mechanism using a feed bin has two options corresponding to the presence of a feed bin on one side (NHPD41) or on both sides of the machine (NHPD42). Each time a new layer of powder is needed, the roller moves to the non-working area, the feed bin rises to a predetermined height and the roller passes above it taking the loose powder to the working area. Thus, there is no need for a mechanism for filling the feed bin with powder since the same was possible with the stationary dosing mechanism. The feed bin will be filled upfront and will contain sufficient powder for the entire working volume of the machine. 
Hybrid designs utilize, in addition to the roller, a doctor blade or a slot feeder. They are proposed for improving quality of the final surface. In non-hybrid designs, the roller will compact an uneven layer of loose powder. By adding either a slot feeder or a doctor blade, the loose powder is first spread evenly by the slot feeder or the doctor blade and the roller will afterwards compact an even layer of loose powder.

\subsection{Evaluation of Alternatives}

For each pairwise comparison of alternatives criteria values were assigned in the range [1,9]. Assignment was based on the authors' knowledge, experience and engineering judgement. The first set of applicable judgement matrix criteria is shown in Table 7. From the numerous pairwise comparison tables a representative set is presented in Table 8 . The remainder can be located in Appendix A.

Table 7. Criteria judgment matrix (first set).

\begin{tabular}{|c|c|c|c|c|c|c|c|}
\hline The Six Criteria & $\mathrm{Cr}_{11}$ & $\mathrm{Cr}_{12}$ & $\mathrm{Cr}_{13}$ & $\mathrm{Cr}_{14}$ & $\mathrm{Cr}_{15}$ & $\mathrm{Cr}_{16}$ & Priority Vector \\
\hline $\mathrm{Cr}_{11}$ & 1 & 6 & 2 & 4 & 5 & 5 & 0.4057 \\
\hline $\mathrm{Cr}_{12}$ & $1 / 6$ & 1 & $1 / 5$ & $1 / 3$ & $1 / 2$ & $1 / 2$ & 0.0467 \\
\hline $\mathrm{Cr}_{13}$ & $1 / 2$ & 5 & 1 & 3 & 4 & 4 & 0.2750 \\
\hline $\mathrm{Cr}_{14}$ & $1 / 4$ & 3 & $1 / 3$ & 1 & 2 & 2 & 0.1237 \\
\hline $\mathrm{Cr}_{15}$ & $1 / 5$ & 2 & $1 / 4$ & $1 / 2$ & 1 & 1 & 0.0744 \\
\hline $\mathrm{Cr}_{16}$ & $1 / 5$ & 2 & $1 / 4$ & $1 / 2$ & 1 & 1 & 0.0744 \\
\hline
\end{tabular}

Table 8. Pairwise comparisons.

\begin{tabular}{|c|c|c|c|c|c|c|c|c|c|}
\hline $\mathrm{Cr}_{11}$ & NHPD11 & NHPD12 & NHPD13 & $\begin{array}{l}\text { Priority } \\
\text { Vector }\end{array}$ & $\mathrm{Cr}_{12}$ & NHPD11 & NHPD12 & NHPD13 & $\begin{array}{c}\text { Priority } \\
\text { Vector }\end{array}$ \\
\hline NHPD11 & 1 & $1 / 6$ & $1 / 6$ & 0.0769 & NHPD11 & 1 & 5 & $1 / 4$ & 0.2370 \\
\hline NHPD12 & 6 & 1 & 1 & 0.4615 & NHPD12 & $1 / 5$ & 1 & $1 / 8$ & 0.0643 \\
\hline NHPD13 & 6 & 1 & 1 & 0.4615 & NHPD13 & 4 & 8 & 1 & 0.6986 \\
\hline \multicolumn{5}{|c|}{$\lambda_{\max }=3, n=3, C R=0<1$ table consistent } & \multicolumn{5}{|c|}{$\lambda_{\max }=3.904, n=3, C R=0.0810<1$ table consistent } \\
\hline $\mathrm{Cr}_{13}$ & NHPD11 & NHPD12 & NHPD13 & $\begin{array}{c}\text { Priority } \\
\text { Vector }\end{array}$ & $\mathrm{Cr}_{14}$ & NHPD11 & NHPD12 & NHPD13 & $\begin{array}{c}\text { Priority } \\
\text { Vector }\end{array}$ \\
\hline NHPD11 & 1 & 3 & 4 & 0.6250 & NHPD11 & 1 & 6 & 4 & 0.6817 \\
\hline NHPD12 & $1 / 3$ & 1 & 2 & 0.2385 & NHPD12 & $1 / 6$ & 1 & $1 / 4$ & 0.0819 \\
\hline NHPD13 & $1 / 4$ & $1 / 2$ & 1 & 0.1365 & NHPD13 & $1 / 4$ & 4 & 1 & 0.2363 \\
\hline \multicolumn{5}{|c|}{$\lambda_{\max }=3.0183, n=3, C R=0.0158<1$ table consistent } & \multicolumn{5}{|c|}{$\lambda_{\max }=3.1078, n=3, C R=0.930<1$ table consistent } \\
\hline $\mathrm{Cr}_{15}$ & NHPD11 & NHPD12 & NHPD13 & $\begin{array}{c}\text { Priority } \\
\text { Vector }\end{array}$ & $\mathrm{Cr}_{16}$ & NHPD11 & NHPD12 & NHPD13 & $\begin{array}{c}\text { Priority } \\
\text { Vector }\end{array}$ \\
\hline NHPD11 & 1 & 7 & 4 & 0.7049 & NHPD11 & 1 & $1 / 6$ & $1 / 3$ & 0.0953 \\
\hline NHPD12 & $1 / 7$ & 1 & $1 / 3$ & 0.0841 & NHPD12 & 6 & 1 & 3 & 0.6548 \\
\hline NHPD13 & $1 / 4$ & 3 & 1 & 0.2109 & NHPD13 & 3 & $1 / 3$ & 1 & 0.2499 \\
\hline \multicolumn{5}{|c|}{$\lambda_{\max }=3.0234, n=3, C R=0.0279<1$ table consistent } & \multicolumn{5}{|c|}{$\lambda_{\max }=3.0183, n=3, C R=0.0158<1$ table consistent } \\
\hline
\end{tabular}

The judgment matrices below are indicative for the vibratory non-hybrid concept designs. Using the same methodology, all pairwise comparisons are performed. According to the analysis, the alternative that is marginally preferable among the three vibratory non hybrid designs is NHPD11, see Table 9, with a priority value of $35.80 \%$ which is slightly higher than the two other alternatives. 
Table 9. Decision matrix NHPD1.

\begin{tabular}{|c|c|c|c|c|c|c|c|}
\hline & & & & Criteria & & & \multirow{3}{*}{$\begin{array}{c}\text { Final } \\
\text { Priority }\end{array}$} \\
\hline & $\mathrm{Cr}_{11}$ & $\mathrm{Cr}_{12}$ & $\mathrm{Cr}_{13}$ & $\mathrm{Cr}_{14}$ & $\mathrm{Cr}_{15}$ & $\mathrm{Cr}_{16}$ & \\
\hline Criteria Weights & 0.4057 & 0.0467 & 0.275 & 0.1237 & 0.0744 & 0.0744 & \\
\hline NHPD11 & 0.0769 & 0.2370 & 0.6250 & 0.6817 & 0.7049 & 0.0953 & 0.3580 \\
\hline NHPD12 & 0.4615 & 0.0643 & 0.2385 & 0.0819 & 0.0841 & 0.6548 & 0.3209 \\
\hline NHPD13 & 0.4615 & 0.6986 & 0.1365 & 0.2363 & 0.2109 & 0.2499 & 0.3209 \\
\hline
\end{tabular}

Using the same methodology, the following designs are selected as the best from each category.

- $\quad$ NHPD22 with priority $53.47 \%$ followed by NHPD21 with $46.15 \%$.

- NHPD33 with priority $44.37 \%$ among the three custom-made dosing mechanism designs.

- $\quad$ NHPD41 with priority $53.54 \%$.

- Designs HPD11, HPD23 and HPD42 were selected yet marginally amongst the alternative designs of each category. Finally, HPD32 design was selected with 53.47\%.

These alternatives will be evaluated using the second set of criteria that has been defined and described in Table 10. For this evaluation, the pairwise judgment matrices can be found in Appendix B.

Table 10. Criteria judgment matrix (second set).

\begin{tabular}{|c|c|c|c|c|c|c|c|c|c|}
\hline The Eight Criteria & $\mathrm{Cr}_{21}$ & $\mathrm{Cr}_{22}$ & $\mathrm{Cr}_{23}$ & $\mathrm{Cr}_{24}$ & $\mathrm{Cr}_{25}$ & $\mathrm{Cr}_{26}$ & $\mathrm{Cr}_{27}$ & $\mathrm{Cr}_{28}$ & Priority Vector \\
\hline $\mathrm{Cr}_{21}$ & 1 & 3 & 2 & 4 & 4 & 4 & 2 & 3 & 0.2808 \\
\hline $\mathrm{Cr}_{22}$ & $1 / 3$ & 1 & $1 / 2$ & 2 & 2 & 2 & $1 / 2$ & 1 & 0.1005 \\
\hline $\mathrm{Cr}_{23}$ & $1 / 2$ & 2 & 1 & 3 & 3 & 3 & 1 & 2 & 0.1740 \\
\hline $\mathrm{Cr}_{24}$ & $1 / 4$ & $1 / 2$ & $1 / 3$ & 1 & 1 & 1 & $1 / 3$ & $1 / 2$ & 0.0567 \\
\hline $\mathrm{Cr}_{25}$ & $1 / 4$ & $1 / 2$ & $1 / 3$ & 1 & 1 & 1 & $1 / 3$ & $1 / 2$ & 0.0567 \\
\hline $\mathrm{Cr}_{26}$ & $1 / 4$ & $1 / 2$ & $1 / 3$ & 1 & 1 & 1 & $1 / 3$ & $1 / 2$ & 0.0567 \\
\hline $\mathrm{Cr}_{27}$ & $1 / 2$ & 2 & 1 & 3 & 3 & 3 & 1 & 2 & 0.1740 \\
\hline $\mathrm{Cr}_{28}$ & $1 / 3$ & 1 & $1 / 2$ & 2 & 2 & 2 & $1 / 2$ & 1 & 0.1005 \\
\hline
\end{tabular}

The judgment matrix with the second set of criteria is presented in Table 11. Figure 4 illustrates the final ranking of the alternative concept designs based on the final priority.

Table 11. Final Decision matrix.

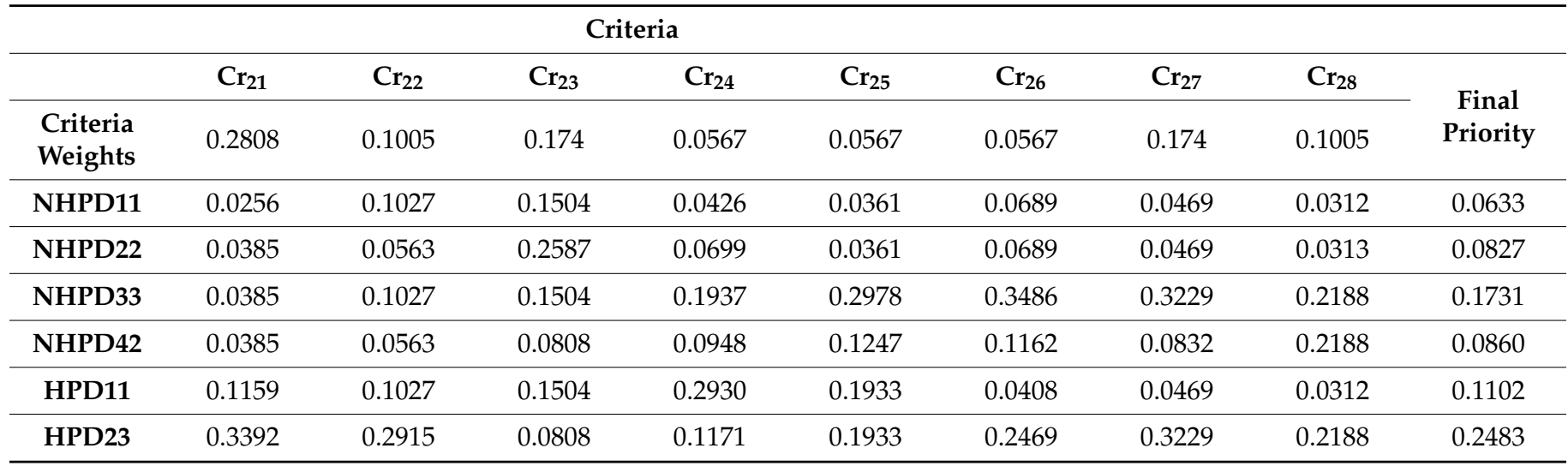


Table 11. Cont.

\begin{tabular}{llllllllll}
\hline HPD32 & 0.1655 & 0.1027 & 0.0808 & 0.0720 & 0.0361 & 0.0408 & 0.0469 & 0.0312 & 0.0905 \\
\hline HPD42 & 0.2382 & 0.1853 & 0.0478 & 0.1171 & 0.0827 & 0.0689 & 0.0832 & 0.2188 & 0.1455 \\
\hline
\end{tabular}

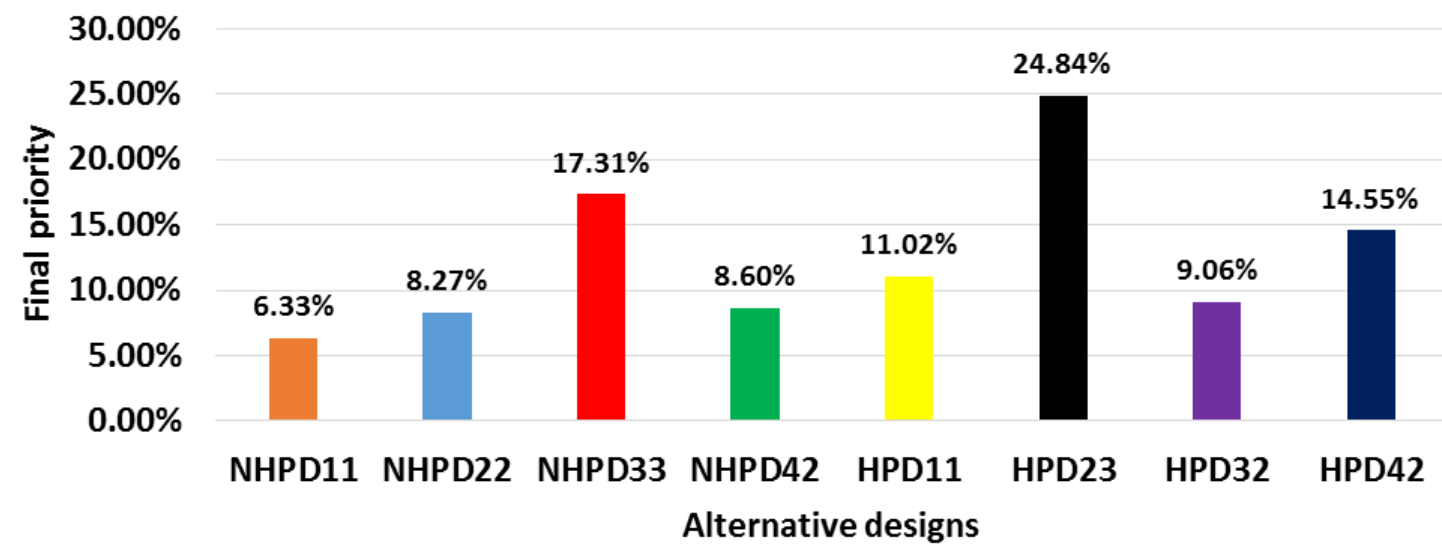

Figure 4. Final priority vs. alternative designs.

According to these results, the "global" best solution is alternative HPD23, which involves a custom-made doser at the stationary position and the roller with doctor blade. The selected alternative priority is well above the others at $24.84 \%$ followed by NHPD33 at $17.31 \%$ and HPD 42 at $14.55 \%$.

\section{PDS Detailed Design and Implementation}

Figure 5 illustrates the complete PDS design on the machine frame. Note that the area of working plate is $285 \mathrm{~mm} \times 285 \mathrm{~mm}$ and its maximum stroke is $140 \mathrm{~mm}$.

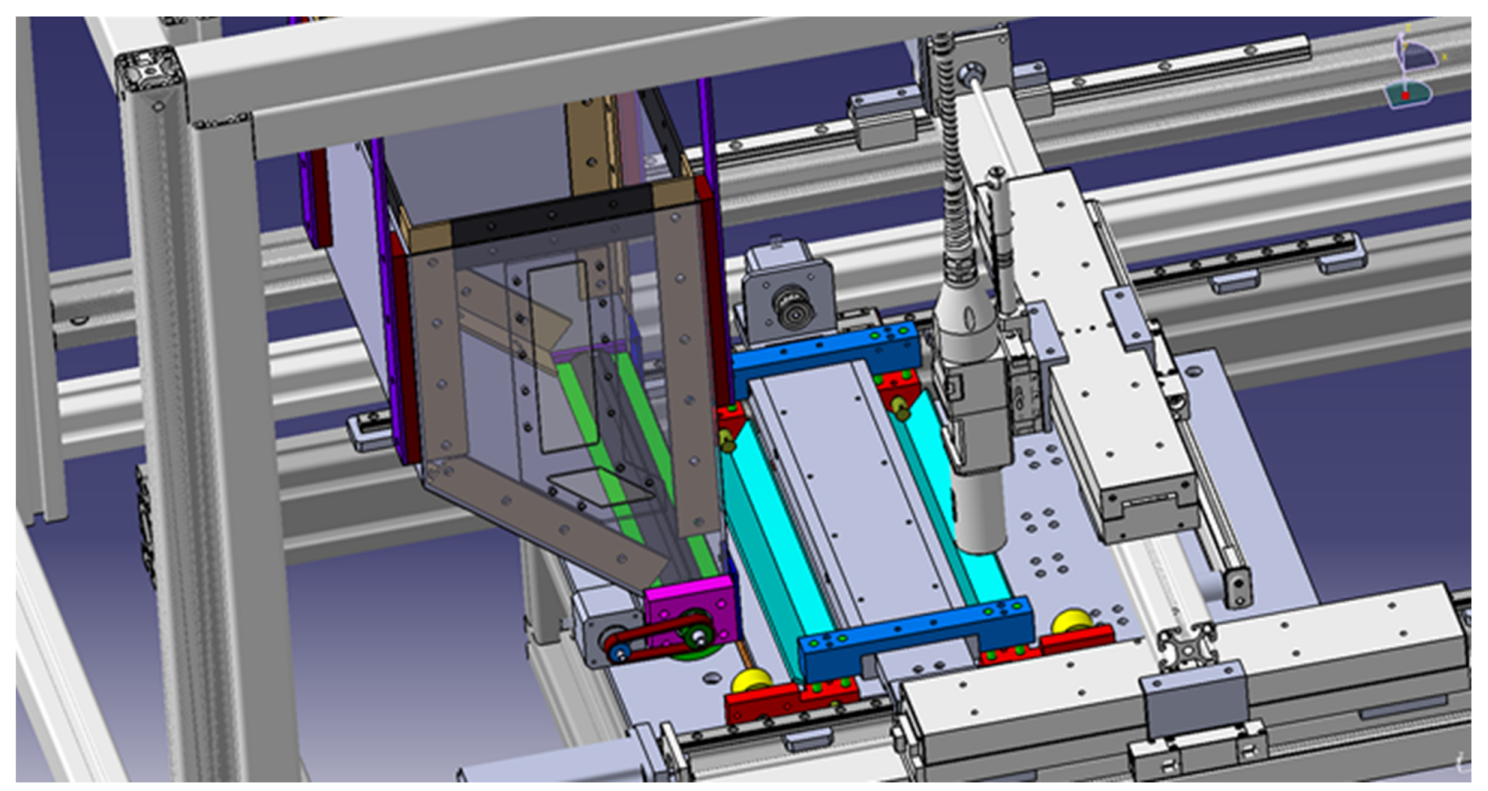

Figure 5. Powder deposition mechanism detailed design.

A brush sealant structure is screw mounted at its periphery within a gap of $2.75 \mathrm{~mm}$ formed sidewise to the respective container wall in order to prevent powder leaks, see Figure 6a. 


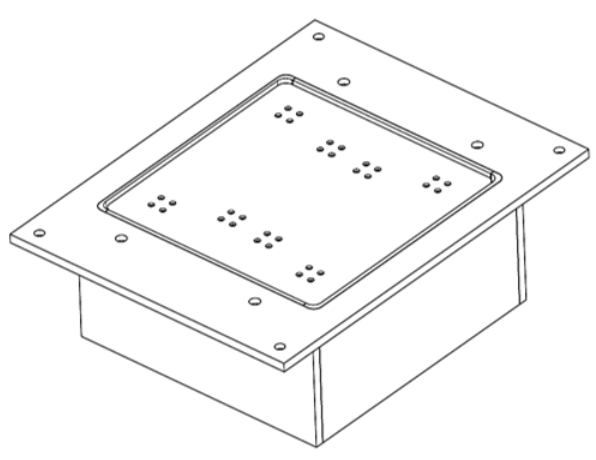

a

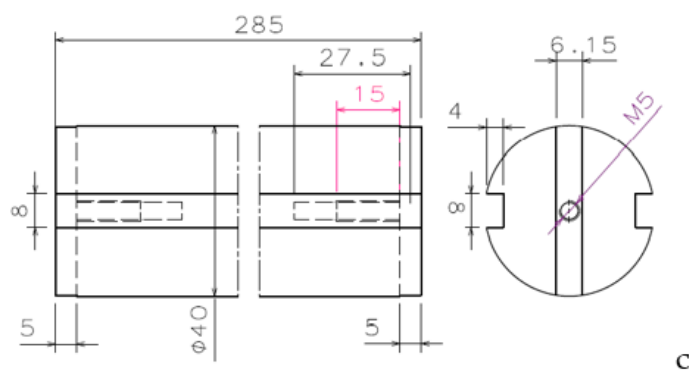

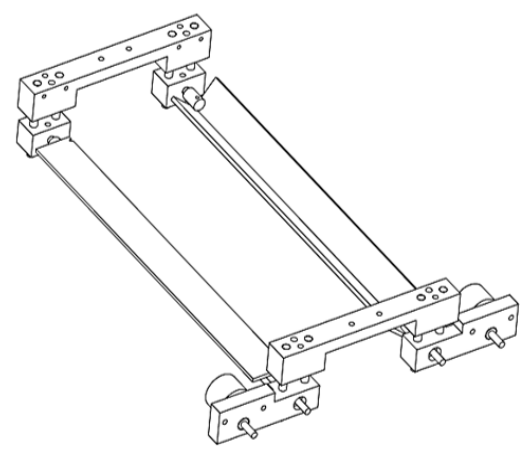

b

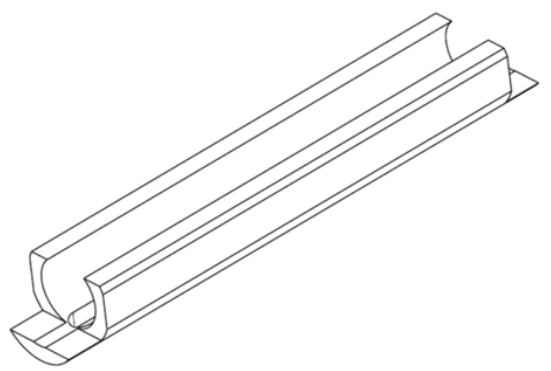

d

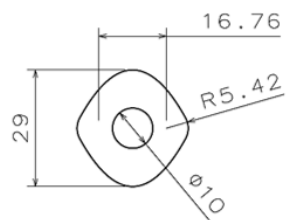

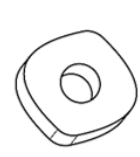

c

Figure 6. Detail designed parts (a) working area plate, container and sealant assembly (b) powder spreading mechanism (c) doser drum (d) doser drum sealing sleeve (e) 2-pulse cam encoder.

The volume of the powder box should be equal or greater than the working area volume. Indeed, the former was designed at $0.01643 \mathrm{~m}^{3}$ whereas the latter was $285 \times 285 \times$ $140=0.01138 \mathrm{~m}^{3}$, i.e., 1.44 times lower. The angle of the container had to be large in order for the powder to flow freely towards the rotating drum. Due to a lack of space, only one side is angled since the vertical side will certainly feed the doser constantly with powder regardless of the level of powder in the container.

The powder doser drum should be capable of providing powder for the thinnest layer to be spread on the powder bed, in this case $20 \mu \mathrm{m}$. The respective volume of loose powder, i.e., $285 \times 285 \times 0.020=1625 \mathrm{~mm}^{3}$. This is spread on the powder bed by an angled roller doser and a doctor blade forming a spreading mechanism, see Figure $6 \mathrm{~b}$. The powder loaded into the angled doser is stored in each one of two axial slots that are machined into the drum's body, see Figure 6c; this powder volume is unloaded to the roller doser upon rotation of the drum from $0^{\circ}$ to $180^{\circ}$ with respect to the vertical direction. The doser drum's sides are sealed by a special flange to prevent powder leakage. The drum is enclosed in a sealing sleeve forming a natural extension of the powder container. The sleeve has a through slot at the bottom from which powder stored in the drum's slots will flow into the powder bed when the two slots overlap, see Figure 6d. A stepping motor is responsible for drum rotation. The control system is informed of the appropriate slot orientation through a two pulse cam encoder, see Figure 6e.

The angled dowser of the spreading mechanism, see Figure $6 \mathrm{~b}$, is rotated gradually by a stepping motor thereby gradually dropping powder onto the powder bed and allowing the doctor blade to level it as the mechanism continuously advances. In fact, a 16 pulse/rev cam encoder similar to the 2 pulse/rev encoder depicted in Figure 6e, delimits the spreading doser's positions of interest for uniform spreading. Note that the second angled doser functions as a doctor blade when oriented by e.g., $135^{\circ}$ or indeed, any other angle in order 
to achieve the desired scooping angle. In fact, the powder spreading mechanism and its angled dosers with powder functional blade edges can be levelled by use of special screws.

The parts were designed on a CATIA V5 system on which the g-codes were also produced utilizing the respective CAM application. The parts were manufactured on a Haas TL-1 lathe and TM-1 milling machines to a general manufacturing tolerance of $10 \mu \mathrm{m}$. The 3 stepping motors of the doser drum $(4.8 \mathrm{~kg} \cdot \mathrm{cm})$ and the spreading dosers $(0.35 \mathrm{~kg} \cdot \mathrm{cm})$ were driven by A4988 drivers controlled by an Arduino Uno ${ }^{\mathrm{TM}}$ microcontroller. In addition, limit switches were used for the spreading doser and the doser drum encoders and were also connected to the microcontroller.

The general view of the assembled system is shown in Figure 7, in which some additional characteristic parts are depicted. Metal parts were made from Al series 2000, whereas the drum and its sleeve were constructed from PVC.

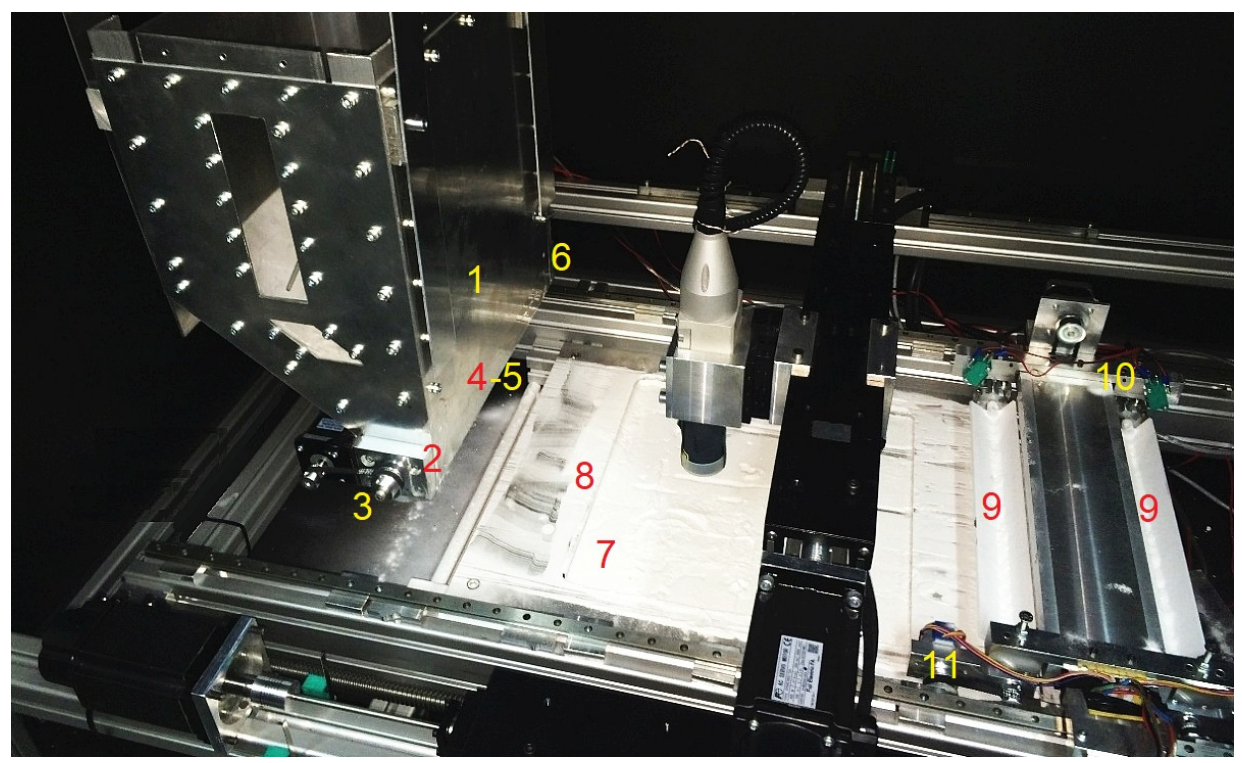

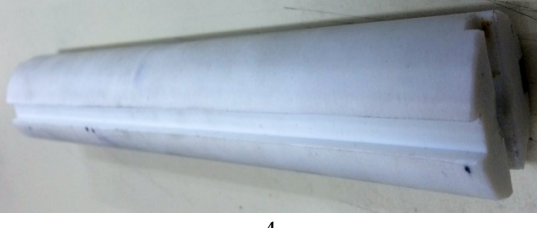

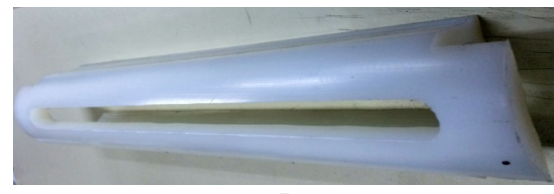

5

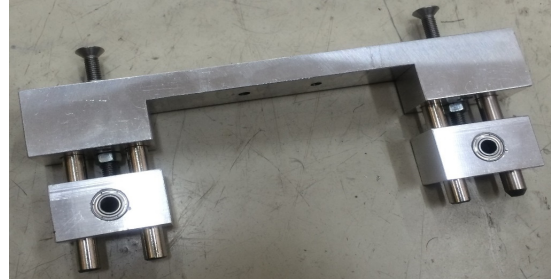

$10 \mathrm{~b}$ (a)
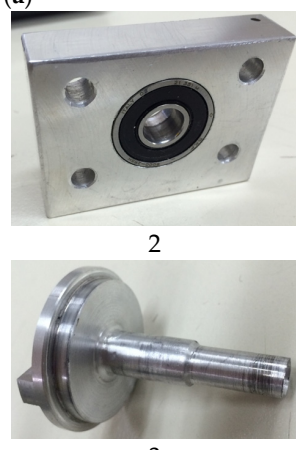

3

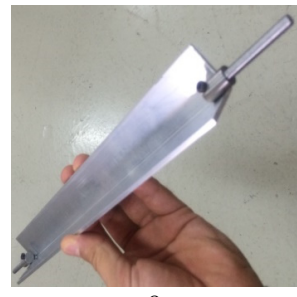

9
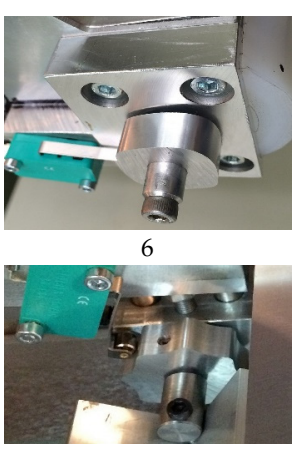

$10 \mathrm{a}$

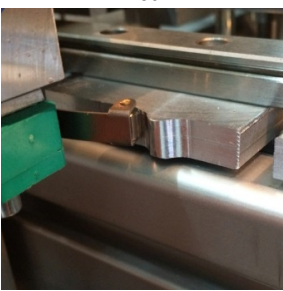

11

(b)

Figure 7. PDS implementation (a) assembly (1: powder container, 2: bearing nest, 3: doser drum shaft, 4: doser drum, 5: doser drum sealing sleeve, 6: doser drum sealing flange and encoder, 7: working area plate, 8: working area plate sealing brush, 9: angled doser, 10: spreading mechanism base (10a) with angled doser encoders (10b), 11: spreading mechanism travel encoder), (b) individual parts manufactured in-house. 
Testing of the system was performed using commercially available ABS powder from StrataSys ${ }^{\mathrm{TM}}$. Feeding of powder to the angled doser functioned as expected, see Figure 8 , as did the powder spreading mechanism. Layer thickness measurements performed after appropriate tuning and improvements are reported in [56]. In particular, white light scanning was used to compare the newly deposited surface layer profile with the previous one for a nominal layer thickness of $100 \mu \mathrm{m}$. Deviations were found within the accuracy range of the measuring equipment used, i.e., $8 \mu \mathrm{m}$. Furthermore, ANOVA method revealed the major influence of deposition speed on surface roughness attained.

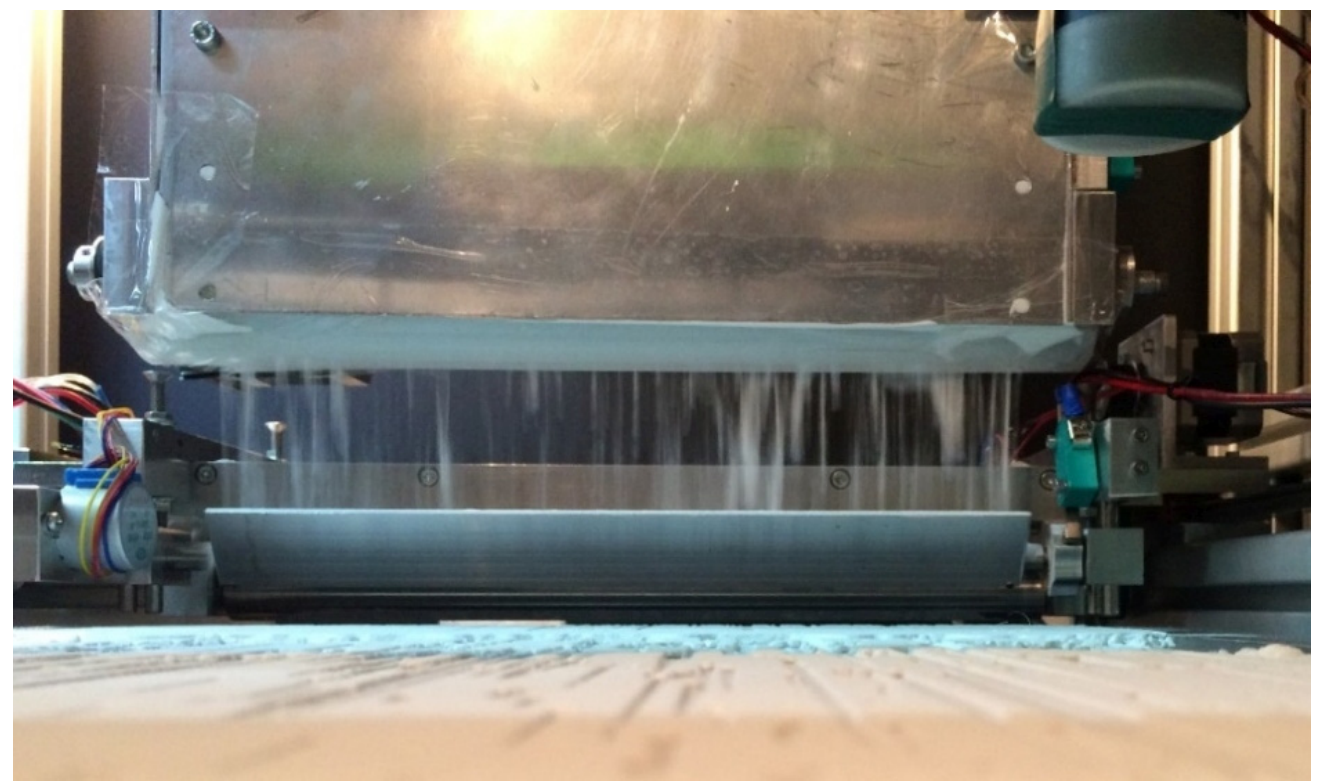

(a)

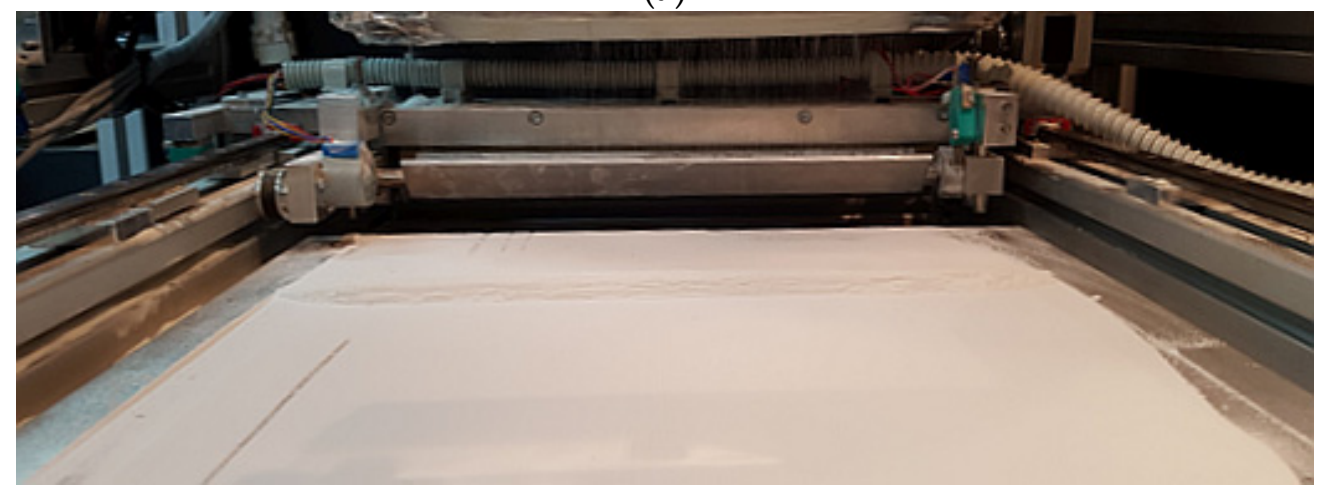

(b)

Figure 8. Characteristic functionality snapshots (a) powder falling into the angled doser (b) powder spread onto working area plate.

\section{Conclusions}

A two-layer Analytic Hierarchy Process (AHP) was proposed for the evaluation of several alternative designs of a powder deposition mechanism of an SLS machine. Numerous alternative concept designs were developed and evaluated using the AHP method. The evaluation procedure was performed in two steps, during the first step the alternative concept designs of the same category were evaluated, and in the second step the best representative of each category that resulted from the first evaluation were compared with each other in order to seek and obtain the global best design. A separate set of criteria for each evaluation step was defined.

The method was simple to execute, however, the difficulty was in objectively assigning values of relative importance to each design, and avoiding bias from subjective factors. 
All pairwise comparison matrices were consistent, representing a sign of coherent criteria value assignment and alleviating subjectivity to a considerable extent. The result obtained from the AHP method was a design that best suited the current application. Without the AHP method or another analogous method, the systematic and objective evaluation of the concept designs would be impossible. Note that another designer employing a different set of criteria may produce a different result; this is by no means a disadvantage of the method, since inherent subjectivity in design criteria is a widely accepted fact.

Detailed design of the mechanism's parts required some experience in kinematic mechanisms and their microprocessor-based control. Their manufacture was not particularly challenging, but it was certainly time consuming despite using CNC machinery. Preliminary experiments on mechanisms installed on the open SLS machine at hand, confirmed its acceptable performance with an optically uniform spread of a consistent powder quantity. This was additionally confirmed by subsequent layer thickness measurements reported in follow-up work.

Author Contributions: Conceptualization, F.P. and G.-C.V.; methodology, F.P.; software, F.P.; validation, F.P.; formal analysis, F.P.; investigation, F.P.; resources, F.P. and G.-C.V.; data curation, F.P.; writing - original draft preparation, F.P.; writing - review and editing, F.P. and G.-C.V.; visualization, F.P. and G.-C.V.; supervision, G.-C.V.; project administration, G.-C.V.; funding acquisition, G.-C.V. All authors have read and agreed to the published version of the manuscript.

Funding: This research received no external funding.

Conflicts of Interest: The authors declare no conflict of interest.

\section{Appendix A}

Table A1. Flat belt mechanism.

\begin{tabular}{|c|c|c|c|c|c|c|c|}
\hline $\mathrm{Cr}_{11}$ & NHPD21 & NHPD22 & $\begin{array}{l}\text { Priority } \\
\text { Vector }\end{array}$ & $\mathrm{Cr}_{14}$ & NHPD21 & NHPD22 & $\begin{array}{c}\text { Priority } \\
\text { Vector }\end{array}$ \\
\hline NHPD21 & 1 & $1 / 5$ & 0.1667 & NHPD21 & 1 & 2 & 0.6667 \\
\hline NHPD22 & 5 & 1 & 0.8333 & NHPD22 & $1 / 2$ & 1 & 0.3333 \\
\hline \multicolumn{4}{|c|}{$\lambda_{\max }=2, n=2, C R=0<1$ table consistent } & \multicolumn{4}{|c|}{$\lambda_{\max }=2, n=2, C R=0<1$ table consistent } \\
\hline $\mathrm{Cr}_{12}$ & NHPD21 & NHPD22 & $\begin{array}{l}\text { Priority } \\
\text { Vector }\end{array}$ & $\mathrm{Cr}_{15}$ & NHPD21 & NHPD22 & $\begin{array}{c}\text { Priority } \\
\text { Vector }\end{array}$ \\
\hline NHPD21 & 1 & 3 & 0.7500 & NHPD21 & 1 & 4 & 0.8000 \\
\hline NHPD22 & $1 / 3$ & 1 & 0.2500 & NHPD22 & $1 / 4$ & 1 & 0.2000 \\
\hline \multicolumn{4}{|c|}{$\lambda_{\max }=2, n=2, C R=0<1$ table consistent } & \multicolumn{4}{|c|}{$\lambda_{\max }=2, n=2, C R=0<1$ table consistent } \\
\hline $\mathrm{Cr}_{13}$ & NHPD21 & NHPD22 & $\begin{array}{l}\text { Priority } \\
\text { Vector }\end{array}$ & $\mathrm{Cr}_{16}$ & NHPD21 & NHPD22 & $\begin{array}{c}\text { Priority } \\
\text { Vector }\end{array}$ \\
\hline NHPD21 & 1 & 2 & 0.6667 & NHPD21 & 1 & 1 & 0.5000 \\
\hline NHPD22 & $1 / 2$ & 1 & 0.3333 & NHPD22 & 1 & 1 & 0.5000 \\
\hline \multicolumn{4}{|c|}{$\lambda_{\max }=2, n=2, C R=0<1$ table consistent } & \multicolumn{4}{|c|}{$\lambda_{\max }=2, n=2, C R=0<1$ table consistent } \\
\hline
\end{tabular}

Decision matrix NHPD2

\begin{tabular}{cccccccc}
\hline & \multicolumn{7}{c}{ Criteria } \\
\hline & $\mathrm{Cr}_{11}$ & $\mathrm{Cr}_{12}$ & $\mathrm{Cr}_{13}$ & $\mathrm{Cr}_{14}$ & $\mathrm{Cr}_{15}$ & $\mathrm{Cr}_{16}$ & Final priority \\
\hline Alt. & 0.4057 & 0.0467 & 0.275 & 0.1237 & 0.0744 & 0.0744 & \\
\hline NHPD21 & 0.1667 & 0.7500 & 0.6667 & 0.6667 & 0.8000 & 0.5000 & 0.4615 \\
\hline NHPD22 & 0.8333 & 0.2500 & 0.3333 & 0.3333 & 0.2000 & 0.5000 & 0.5347 \\
\hline
\end{tabular}


Table A2. Custom made dosing mechanism.

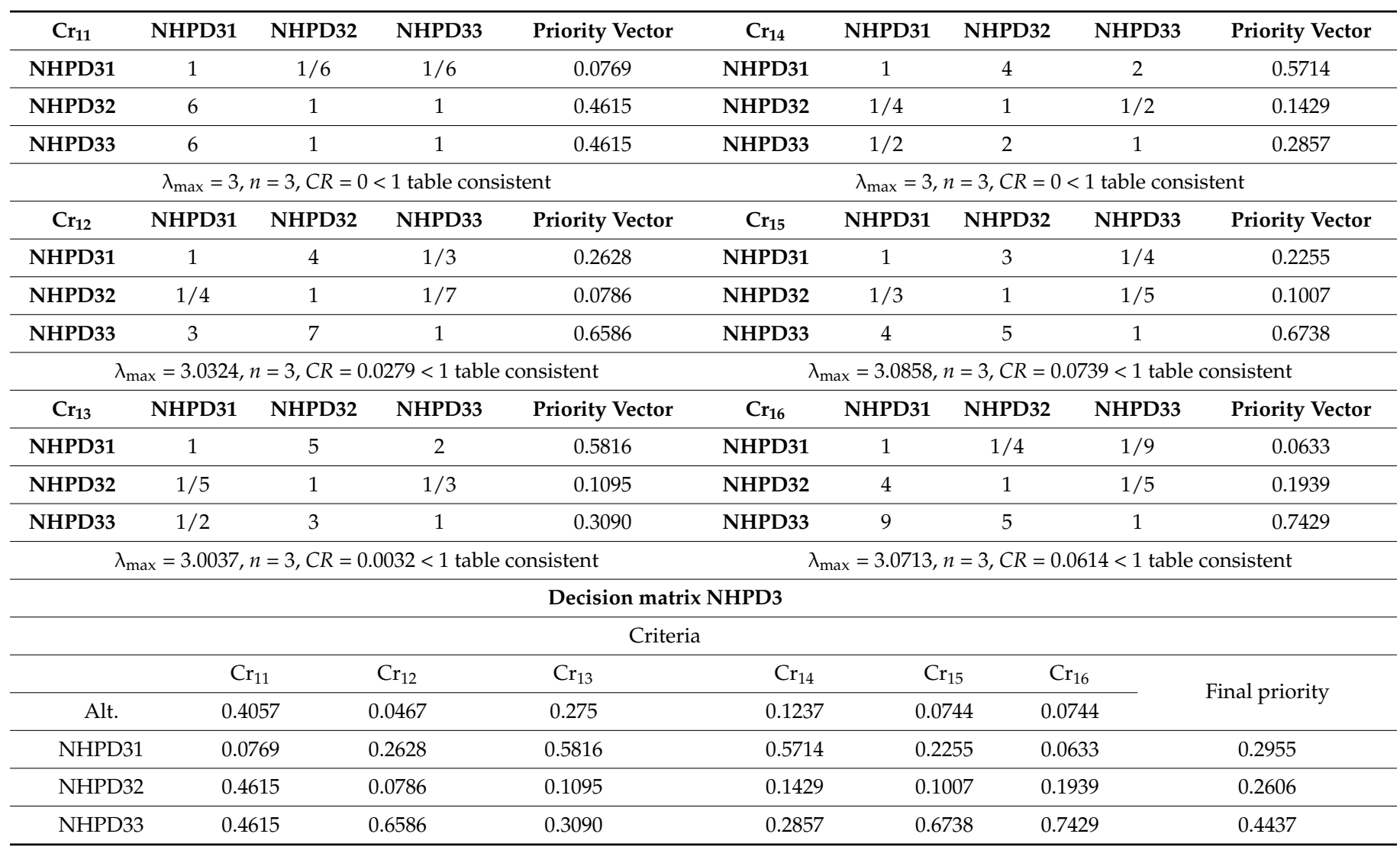

Table A3. Powder deposition using a feed bin.

\begin{tabular}{|c|c|c|c|c|c|c|c|}
\hline $\mathrm{Cr}_{11}$ & NHPD41 & NHPD42 & $\begin{array}{c}\text { Priority } \\
\text { Vector }\end{array}$ & $\mathrm{Cr}_{14}$ & NHPD41 & NHPD42 & $\begin{array}{c}\text { Priority } \\
\text { Vector }\end{array}$ \\
\hline NHPD41 & 1 & $1 / 5$ & 0.1667 & NHPD41 & 1 & 3 & 0.7500 \\
\hline NHPD42 & 5 & 1 & 0.8333 & NHPD42 & $1 / 3$ & 1 & 0.2500 \\
\hline \multicolumn{4}{|c|}{$\lambda_{\max }=2, n=2, C R=0<1$ table consistent } & \multicolumn{4}{|c|}{$\lambda_{\max }=2, n=2, C R=0<1$ table consistent } \\
\hline $\mathrm{Cr}_{12}$ & NHPD41 & NHPD42 & $\begin{array}{c}\text { Priority } \\
\text { Vector }\end{array}$ & $\mathrm{Cr}_{15}$ & NHPD41 & NHPD42 & $\begin{array}{c}\text { Priority } \\
\text { Vector }\end{array}$ \\
\hline NHPD41 & 1 & 1 & 0.5000 & NHPD41 & 1 & 2 & 0.6667 \\
\hline NHPD42 & 1 & 1 & 0.5000 & NHPD42 & $1 / 2$ & 1 & 0.3333 \\
\hline \multicolumn{4}{|c|}{$\lambda_{\max }=2, n=2, C R=0<1$ table consistent } & \multicolumn{4}{|c|}{$\lambda_{\max }=2, n=2, C R=0<1$ table consistent } \\
\hline $\mathrm{Cr}_{13}$ & NHPD41 & NHPD42 & $\begin{array}{c}\text { Priority } \\
\text { Vector }\end{array}$ & $\mathrm{Cr}_{16}$ & NHPD41 & NHPD42 & $\begin{array}{c}\text { Priority } \\
\text { Vector }\end{array}$ \\
\hline NHPD41 & 1 & 3 & 0.7500 & NHPD41 & 1 & $1 / 2$ & 0.3333 \\
\hline NHPD42 & $1 / 3$ & 1 & 0.2500 & NHPD42 & 2 & 1 & 0.6667 \\
\hline \multicolumn{4}{|c|}{$\lambda_{\max }=2, n=2, C R=0<1$ table consistent } & \multicolumn{4}{|c|}{$\lambda_{\max }=2, n=2, C R=0<1$ table consistent } \\
\hline \multicolumn{8}{|c|}{ Decision matrix NHPD4 } \\
\hline \multicolumn{8}{|c|}{ Criteria } \\
\hline & $\mathrm{Cr}_{11}$ & $\mathrm{Cr}_{12}$ & $\mathrm{Cr}_{13}$ & $\mathrm{Cr}_{14}$ & $\mathrm{Cr}_{15}$ & $\mathrm{Cr}_{16}$ & \multirow{2}{*}{ Final priority } \\
\hline Alt. & 0.4057 & 0.0467 & 0.275 & 0.1237 & 0.0744 & 0.0744 & \\
\hline NHPD41 & 0.1667 & 0.5000 & 0.7500 & 0.7500 & 0.6667 & 0.3333 & 0.4644 \\
\hline NHPD42 & 0.8333 & 0.5000 & 0.2500 & 0.2500 & 0.3333 & 0.6667 & 0.5354 \\
\hline
\end{tabular}


Table A4. Slot feeder deposition.

\begin{tabular}{|c|c|c|c|c|c|c|c|c|c|}
\hline $\mathrm{Cr}_{11}$ & HPD11 & HPD12 & HPD13 & Priority Vector & $\mathrm{Cr}_{14}$ & HPD11 & HPD12 & HPD13 & Priority Vector \\
\hline HPD11 & 1 & $1 / 6$ & $1 / 6$ & 0.0769 & HPD11 & 1 & 5 & 3 & 0.6370 \\
\hline HPD12 & 6 & 1 & 1 & 0.4615 & HPD12 & $1 / 5$ & 1 & $1 / 3$ & 0.1047 \\
\hline HPD13 & 6 & 1 & 1 & 0.4615 & HPD13 & $1 / 3$ & 3 & 1 & 0.2583 \\
\hline \multicolumn{5}{|c|}{$\lambda_{\max }=3, n=3, C R=0<1$ table consistent } & \multicolumn{5}{|c|}{$\lambda_{\max }=3.0385, n=3, C R=0.0332<1$ table consistent } \\
\hline $\mathrm{Cr}_{12}$ & HPD11 & HPD12 & HPD13 & Priority Vector & $\mathrm{Cr}_{15}$ & HPD11 & HPD12 & HPD13 & Priority Vector \\
\hline HPD11 & 1 & 5 & $1 / 4$ & 0.2370 & HPD11 & 1 & 6 & 4 & 0.7010 \\
\hline HPD12 & $1 / 5$ & 1 & $1 / 8$ & 0.0643 & HPD12 & $1 / 6$ & 1 & $1 / 2$ & 0.1061 \\
\hline HPD13 & 4 & 8 & 1 & 0.6986 & HPD13 & $1 / 4$ & 2 & 1 & 0.1929 \\
\hline \multicolumn{5}{|c|}{$\lambda_{\max }=3.0324, n=3, C R=0.0279<1$ table consistent } & \multicolumn{5}{|c|}{$\lambda_{\max }=3.0092, n=3, C R=0.0079<1$ table consistent } \\
\hline $\mathrm{Cr}_{13}$ & HPD11 & HPD12 & HPD13 & Priority Vector & $\mathrm{Cr}_{16}$ & HPD11 & HPD12 & HPD13 & Priority Vector \\
\hline HPD11 & 1 & 3 & 4 & 0.6250 & HPD11 & 1 & $1 / 7$ & 1 & 0.1111 \\
\hline HPD12 & $1 / 3$ & 1 & 2 & 0.2385 & HPD12 & 7 & 1 & 7 & 0.7778 \\
\hline HPD13 & $1 / 4$ & $1 / 2$ & 1 & 0.1365 & HPD13 & 1 & $1 / 7$ & 1 & 0.1111 \\
\hline \multicolumn{5}{|c|}{$\lambda_{\max }=3.0037, n=3, C R=0.0032<1$ table consistent } & \multicolumn{5}{|c|}{$\lambda_{\max }=3, n=3, C R=0<1$ table consistent } \\
\hline \multicolumn{10}{|c|}{ Decision matrix HPD1 } \\
\hline \multicolumn{10}{|c|}{ Criteria } \\
\hline & \multicolumn{2}{|c|}{$\mathrm{Cr}_{11}$} & $\mathrm{Cr}_{12}$ & $\mathrm{Cr}_{13}$ & $\mathrm{Cr}_{14}$ & \multicolumn{2}{|c|}{$\mathrm{Cr}_{15}$} & & \multirow{2}{*}{ Final priority } \\
\hline Alt. & \multicolumn{2}{|c|}{0.4057} & 0.0467 & 0.275 & 0.1237 & \multicolumn{2}{|c|}{0.0744} & & \\
\hline HPD11 & \multicolumn{2}{|c|}{0.0769} & 0.2370 & 0.6250 & 0.6370 & \multicolumn{2}{|c|}{0.7010} & & 0.3533 \\
\hline HPD12 & \multicolumn{2}{|c|}{0.4615} & 0.0643 & 0.2385 & 0.1047 & & & & 0.3345 \\
\hline HPD13 & 0.4 & & 0.6986 & 0.1365 & 0.2583 & & & & 0.3119 \\
\hline
\end{tabular}

Table A5. Custom-made dosing mechanism with a doctor blade.

\begin{tabular}{|c|c|c|c|c|c|c|c|c|c|}
\hline $\mathrm{Cr}_{11}$ & HPD21 & HPD22 & HPD23 & $\begin{array}{c}\text { Priority } \\
\text { Vector }\end{array}$ & $\mathrm{Cr}_{14}$ & HPD21 & HPD22 & HPD23 & Priority Vector \\
\hline HPD21 & 1 & $1 / 6$ & $1 / 6$ & 0.0769 & HPD21 & 1 & 4 & 2 & 0.5714 \\
\hline HPD22 & 6 & 1 & 1 & 0.4615 & HPD22 & $1 / 4$ & 1 & $1 / 2$ & 0.1429 \\
\hline HPD23 & 6 & 1 & 1 & 0.4615 & HPD23 & $1 / 2$ & 2 & 1 & 0.2857 \\
\hline \multicolumn{5}{|c|}{$\lambda_{\max }=3, n=3, C R=0<1$ table consistent } & \multicolumn{5}{|c|}{$\lambda_{\max }=3.0385, n=3, C R=0.0332<1$ table consistent } \\
\hline $\mathrm{Cr}_{12}$ & HPD21 & HPD22 & HPD23 & $\begin{array}{c}\text { Priority } \\
\text { Vector }\end{array}$ & $\mathrm{Cr}_{15}$ & HPD21 & HPD22 & HPD23 & Priority Vector \\
\hline HPD21 & 1 & 4 & $1 / 3$ & 0.2628 & HPD21 & 1 & 6 & 3 & 0.6548 \\
\hline HPD22 & $1 / 4$ & 1 & $1 / 7$ & 0.0786 & HPD22 & $1 / 6$ & 1 & $1 / 3$ & 0.0953 \\
\hline HPD23 & 3 & 7 & 1 & 0.6586 & HPD23 & $1 / 3$ & 3 & 1 & 0.2499 \\
\hline \multicolumn{5}{|c|}{$\lambda_{\max }=3.0324, n=3, C R=0.0279<1$ table consistent } & \multicolumn{5}{|c|}{$\lambda_{\max }=3.0183, n=3, C R=0.0158<1$ table consistent } \\
\hline $\mathrm{Cr}_{13}$ & HPD21 & HPD22 & HPD23 & $\begin{array}{l}\text { Priority } \\
\text { Vector }\end{array}$ & $\mathrm{Cr}_{16}$ & HPD21 & HPD22 & HPD23 & Priority Vector \\
\hline HPD21 & 1 & 5 & 2 & 0.5816 & HPD21 & 1 & $1 / 4$ & $1 / 9$ & 0.0633 \\
\hline HPD22 & $1 / 5$ & 1 & $1 / 3$ & 0.1095 & HPD22 & 4 & 1 & $1 / 5$ & 0.1939 \\
\hline HPD23 & $1 / 2$ & 3 & 1 & 0.3090 & HPD23 & 9 & 5 & 1 & 0.7429 \\
\hline \multicolumn{5}{|c|}{$\lambda_{\max }=3.0037, n=3, C R=0.0032<1$ table consistent } & \multicolumn{5}{|c|}{$\lambda_{\max }=3, n=3, C R=0<1$ table consistent } \\
\hline
\end{tabular}


Table A5. Cont.

\begin{tabular}{|c|c|c|c|c|c|c|c|}
\hline \multicolumn{8}{|c|}{ Decision matrix HPD2 } \\
\hline & & & & & & & \\
\hline & $\mathrm{Cr}_{11}$ & $\mathrm{Cr}_{12}$ & $\mathrm{Cr}_{13}$ & $\mathrm{Cr}_{14}$ & $\mathrm{Cr}_{15}$ & $\mathrm{Cr}_{16}$ & \multirow{2}{*}{ Final priority } \\
\hline Alt. & 0.4057 & 0.0467 & 0.275 & 0.1237 & 0.0744 & 0.0744 & \\
\hline HPD21 & 0.0769 & 0.2628 & 0.5816 & 0.5714 & 0.6548 & 0.0633 & 0.3275 \\
\hline HPD22 & 0.4615 & 0.0786 & 0.1095 & 0.1429 & 0.0953 & 0.1939 & 0.2602 \\
\hline HPD23 & 0.4615 & 0.6586 & 0.3090 & 0.2857 & 0.2499 & 0.7429 & 0.4121 \\
\hline
\end{tabular}

Table A6. Powder deposition using a flat belt and a doctor blade.

\begin{tabular}{|c|c|c|c|c|c|c|c|}
\hline $\mathrm{Cr}_{11}$ & HPD31 & HPD32 & $\begin{array}{c}\text { Priority } \\
\text { Vector }\end{array}$ & $\mathrm{Cr}_{14}$ & HPD31 & HPD32 & $\begin{array}{l}\text { Priority } \\
\text { Vector }\end{array}$ \\
\hline HPD31 & 1 & $1 / 5$ & 0.1667 & HPD31 & 1 & 2 & 0.6667 \\
\hline HPD32 & 5 & 1 & 0.8333 & HPD32 & $1 / 2$ & 1 & 0.3333 \\
\hline \multicolumn{4}{|c|}{$\lambda_{\max }=2, n=2, C R=0<1$ table consistent } & \multicolumn{4}{|c|}{$\lambda_{\max }=2, n=2, C R=0<1$ table consistent } \\
\hline $\mathrm{Cr}_{12}$ & HPD31 & HPD32 & $\begin{array}{c}\text { Priority } \\
\text { Vector }\end{array}$ & $\mathrm{Cr}_{15}$ & HPD31 & HPD32 & $\begin{array}{l}\text { Priority } \\
\text { Vector }\end{array}$ \\
\hline HPD31 & 1 & 3 & 0.7500 & HPD31 & 1 & 4 & 0.8000 \\
\hline HPD32 & $1 / 3$ & 1 & 0.2500 & HPD32 & $1 / 4$ & 1 & 0.2000 \\
\hline \multicolumn{4}{|c|}{$\lambda_{\max }=2, n=2, C R=0<1$ table consistent } & \multicolumn{4}{|c|}{$\lambda_{\max }=2, n=2, C R=0<1$ table consistent } \\
\hline $\mathrm{Cr}_{13}$ & HPD31 & HPD32 & $\begin{array}{c}\text { Priority } \\
\text { Vector }\end{array}$ & $\mathrm{Cr}_{16}$ & HPD31 & HPD32 & $\begin{array}{c}\text { Priority } \\
\text { Vector }\end{array}$ \\
\hline HPD31 & 1 & 2 & 0.6667 & HPD31 & 1 & 1 & 0.5000 \\
\hline HPD32 & $1 / 2$ & 1 & 0.3333 & HPD32 & 1 & 1 & 0.5000 \\
\hline \multicolumn{4}{|c|}{$\lambda_{\max }=2, n=2, C R=0<1$ table consistent } & \multicolumn{4}{|c|}{$\lambda_{\max }=2, n=2, C R=0<1$ table consistent } \\
\hline \multicolumn{8}{|c|}{ Decision matrix NHPD2 } \\
\hline \multicolumn{8}{|c|}{ Criteria } \\
\hline & $\mathrm{Cr}_{11}$ & $\mathrm{Cr}_{12}$ & $\mathrm{Cr}_{13}$ & $\mathrm{Cr}_{14}$ & $\mathrm{Cr}_{15}$ & $\mathrm{Cr}_{16}$ & \multirow{2}{*}{ Final priority } \\
\hline Alt. & 0.4057 & 0.0467 & 0.275 & 0.1237 & 0.0744 & 0.0744 & \\
\hline HPD31 & 0.1667 & 0.7500 & 0.6667 & 0.6667 & 0.8000 & 0.5000 & 0.4615 \\
\hline HPD32 & 0.8333 & 0.2500 & 0.3333 & 0.3333 & 0.2000 & 0.5000 & 0.5347 \\
\hline
\end{tabular}

Table A7. Feed bin method with a doctor blade.

\begin{tabular}{|c|c|c|c|c|c|c|c|}
\hline $\mathrm{Cr}_{11}$ & HPD41 & HPD42 & $\begin{array}{l}\text { Priority } \\
\text { Vector }\end{array}$ & $\mathrm{Cr}_{14}$ & HPD41 & HPD42 & $\begin{array}{l}\text { Priority } \\
\text { Vector }\end{array}$ \\
\hline HPD41 & 1 & $1 / 5$ & 0.1667 & HPD41 & 1 & 3 & 0.7500 \\
\hline HPD42 & 5 & 1 & 0.8333 & HPD42 & $1 / 3$ & 1 & 0.2500 \\
\hline \multicolumn{4}{|c|}{$\lambda_{\max }=2, n=2, C R=0<1$ table consistent } & \multicolumn{4}{|c|}{$\lambda_{\max }=2, n=2, C R=0<1$ table consistent } \\
\hline $\mathrm{Cr}_{12}$ & HPD41 & HPD42 & $\begin{array}{l}\text { Priority } \\
\text { Vector }\end{array}$ & $\mathrm{Cr}_{15}$ & HPD41 & HPD42 & $\begin{array}{c}\text { Priority } \\
\text { Vector }\end{array}$ \\
\hline HPD41 & 1 & 1 & 0.5000 & HPD41 & 1 & 2 & 0.6667 \\
\hline HPD42 & 1 & 1 & 0.5000 & HPD42 & $1 / 2$ & 1 & 0.3333 \\
\hline \multicolumn{4}{|c|}{$\lambda_{\max }=2, n=2, C R=0<1$ table consistent } & \multicolumn{4}{|c|}{$\lambda_{\max }=2, n=2, C R=0<1$ table consistent } \\
\hline
\end{tabular}


Table A7. Cont.

\begin{tabular}{|c|c|c|c|c|c|c|c|}
\hline $\mathrm{Cr}_{13}$ & HPD41 & HPD42 & $\begin{array}{c}\text { Priority } \\
\text { Vector }\end{array}$ & $\mathrm{Cr}_{16}$ & HPD41 & HPD42 & $\begin{array}{c}\text { Priority } \\
\text { Vector }\end{array}$ \\
\hline HPD41 & 1 & 3 & 0.7500 & HPD41 & 1 & $1 / 2$ & 0.3333 \\
\hline HPD42 & $1 / 3$ & 1 & 0.2500 & HPD42 & 2 & 1 & 0.6667 \\
\hline \multicolumn{4}{|c|}{$\lambda_{\max }=2, n=2, C R=0<1$ table consistent } & \multicolumn{4}{|c|}{$\lambda_{\max }=2, n=2, C R=0<1$ table consistent } \\
\hline \multicolumn{8}{|c|}{ Decision matrix NHPD4 } \\
\hline \multicolumn{8}{|c|}{ Criteria } \\
\hline & $\mathrm{Cr}_{11}$ & $\mathrm{Cr}_{12}$ & $\mathrm{Cr}_{13}$ & $\mathrm{Cr}_{14}$ & $\mathrm{Cr}_{15}$ & $\mathrm{Cr}_{16}$ & \multirow{2}{*}{ Final priority } \\
\hline Alt. & 0.4057 & 0.0467 & 0.275 & 0.1237 & 0.0744 & 0.0744 & \\
\hline HPD41 & 0.1667 & 0.5000 & 0.7500 & 0.7500 & 0.6667 & 0.3333 & 0.4644 \\
\hline HPD42 & 0.8333 & 0.5000 & 0.2500 & 0.2500 & 0.3333 & 0.6667 & 0.5354 \\
\hline
\end{tabular}

\section{Appendix B}

Table A8. Judgment matrix $\mathrm{Cr}_{21}$ Surface quality (final decision).

\begin{tabular}{|c|c|c|c|c|c|c|c|c|c|}
\hline $\mathrm{Cr}_{21}$ & NHPD11 & NHPD22 & NHPD33 & NHPD42 & HPD11 & HPD23 & HPD32 & HPD42 & $\begin{array}{c}\text { Priority } \\
\text { Vector }\end{array}$ \\
\hline NHPD11 & 1 & $1 / 2$ & $1 / 2$ & $1 / 2$ & $1 / 5$ & $1 / 8$ & $1 / 6$ & $1 / 7$ & 0.0256 \\
\hline NHPD22 & 2 & 1 & 1 & 1 & $1 / 4$ & $1 / 7$ & $1 / 5$ & $1 / 6$ & 0.0385 \\
\hline NHPD33 & 2 & 1 & 1 & 1 & $1 / 4$ & $1 / 7$ & $1 / 5$ & $1 / 6$ & 0.0385 \\
\hline NHPD42 & 2 & 1 & 1 & 1 & $1 / 4$ & $1 / 7$ & $1 / 5$ & $1 / 6$ & 0.0385 \\
\hline HPD11 & 5 & 4 & 4 & 4 & 1 & $1 / 4$ & $1 / 2$ & $1 / 3$ & 0.1159 \\
\hline HPD23 & 8 & 7 & 7 & 7 & 4 & 1 & 3 & 2 & 0.3392 \\
\hline HPD32 & 6 & 5 & 5 & 5 & 2 & $1 / 3$ & 1 & $1 / 2$ & 0.1655 \\
\hline HPD42 & 7 & 6 & 6 & 6 & 3 & $1 / 2$ & 2 & 1 & 0.2382 \\
\hline
\end{tabular}

Table A9. Judgment matrix $\mathrm{Cr}_{22}$ Experimental interest (final decision).

\begin{tabular}{|c|c|c|c|c|c|c|c|c|c|}
\hline $\mathrm{Cr}_{22}$ & NHPD11 & NHPD22 & NHPD33 & NHPD42 & HPD11 & HPD23 & HPD32 & HPD42 & $\begin{array}{c}\text { Priority } \\
\text { Vector }\end{array}$ \\
\hline NHPD11 & 1 & 2 & 1 & 2 & 1 & $1 / 3$ & 1 & $1 / 2$ & 0.1027 \\
\hline NHPD22 & $1 / 2$ & 1 & $1 / 2$ & 1 & $1 / 2$ & $1 / 4$ & $1 / 2$ & $1 / 3$ & 0.0563 \\
\hline NHPD33 & 1 & 2 & 1 & 2 & 1 & $1 / 3$ & 1 & $1 / 2$ & 0.1027 \\
\hline NHPD42 & $1 / 2$ & 1 & $1 / 2$ & 1 & $1 / 2$ & $1 / 4$ & $1 / 2$ & $1 / 3$ & 0.0563 \\
\hline HPD11 & 1 & 2 & 1 & 2 & 1 & $1 / 3$ & 1 & $1 / 2$ & 0.1027 \\
\hline HPD23 & 3 & 4 & 3 & 4 & 3 & 1 & 3 & 2 & 0.2915 \\
\hline HPD32 & 1 & 2 & 1 & 2 & 1 & $1 / 3$ & 1 & $1 / 2$ & 0.1027 \\
\hline HPD42 & 2 & 3 & 2 & 3 & 2 & $1 / 2$ & 2 & 1 & 0.1853 \\
\hline \multicolumn{10}{|c|}{$\lambda_{\max }=8.0415, n=8, C R=0.0042<1$ table consistent } \\
\hline
\end{tabular}


Table A10. Judgment matrix $\mathrm{Cr}_{23}$ Cost (final decision).

\begin{tabular}{|c|c|c|c|c|c|c|c|c|c|}
\hline $\mathrm{Cr}_{23}$ & NHPD11 & NHPD22 & NHPD33 & NHPD42 & HPD11 & HPD23 & HPD32 & HPD42 & $\begin{array}{c}\text { Priority } \\
\text { Vector }\end{array}$ \\
\hline NHPD11 & 1 & $1 / 2$ & 1 & 2 & 1 & 2 & 2 & 3 & 0.1504 \\
\hline NHPD22 & 2 & 1 & 2 & 3 & 2 & 3 & 3 & 4 & 0.2587 \\
\hline NHPD33 & 1 & $1 / 2$ & 1 & 2 & 1 & 2 & 2 & 3 & 0.1504 \\
\hline NHPD42 & $1 / 2$ & $1 / 3$ & $1 / 2$ & 1 & $1 / 2$ & 1 & 1 & 2 & 0.0808 \\
\hline HPD11 & 1 & $1 / 2$ & 1 & 2 & 1 & 2 & 2 & 3 & 0.1504 \\
\hline HPD23 & $1 / 2$ & $1 / 3$ & $1 / 2$ & 1 & $1 / 2$ & 1 & 1 & 2 & 0.0808 \\
\hline HPD32 & $1 / 2$ & $1 / 3$ & $1 / 2$ & 1 & $1 / 2$ & 1 & 1 & 2 & 0.0808 \\
\hline HPD42 & $1 / 3$ & $1 / 4$ & $1 / 3$ & $1 / 2$ & $1 / 3$ & $1 / 2$ & $1 / 2$ & 1 & 0.0478 \\
\hline
\end{tabular}

Table A11. Judgment matrix $\mathrm{Cr}_{24}$ Manufacturability (final decision).

\begin{tabular}{|c|c|c|c|c|c|c|c|c|c|}
\hline $\mathrm{Cr}_{24}$ & NHPD11 & NHPD22 & NHPD33 & NHPD42 & HPD11 & HPD23 & HPD32 & HPD42 & $\begin{array}{c}\text { Priority } \\
\text { Vector }\end{array}$ \\
\hline NHPD11 & 1 & $1 / 2$ & $1 / 4$ & $1 / 3$ & $1 / 5$ & $1 / 3$ & 1 & $1 / 3$ & 0.0426 \\
\hline NHPD22 & 2 & 1 & $1 / 3$ & $1 / 2$ & $1 / 4$ & $1 / 2$ & 2 & $1 / 2$ & 0.0699 \\
\hline NHPD33 & 4 & 3 & 1 & 2 & $1 / 2$ & 2 & 4 & 2 & 0.1937 \\
\hline NHPD42 & 3 & 2 & $1 / 2$ & 1 & $1 / 3$ & 1 & $1 / 3$ & 1 & 0.0948 \\
\hline HPD11 & 5 & 4 & 2 & 3 & 1 & 3 & 5 & 3 & 0.2930 \\
\hline HPD23 & 3 & 2 & $1 / 2$ & 1 & $1 / 3$ & 1 & 3 & 1 & 0.1171 \\
\hline HPD32 & 1 & $1 / 2$ & $1 / 4$ & 3 & $1 / 5$ & $1 / 3$ & 1 & $1 / 3$ & 0.0720 \\
\hline HPD42 & 3 & 2 & $1 / 2$ & 1 & $1 / 3$ & 1 & 3 & 1 & 0.1171 \\
\hline
\end{tabular}

Table A12. Judgment matrix $\mathrm{Cr}_{25}$ Complexity (final decision).

\begin{tabular}{|c|c|c|c|c|c|c|c|c|c|}
\hline $\mathrm{Cr}_{25}$ & NHPD11 & NHPD22 & NHPD33 & NHPD42 & HPD11 & HPD23 & HPD32 & HPD42 & $\begin{array}{c}\text { Priority } \\
\text { Vector }\end{array}$ \\
\hline NHPD11 & 1 & 1 & $1 / 6$ & $1 / 4$ & $1 / 5$ & $1 / 5$ & 1 & $1 / 3$ & 0.0361 \\
\hline NHPD22 & 1 & 1 & $1 / 6$ & $1 / 4$ & $1 / 5$ & $1 / 5$ & 1 & $1 / 3$ & 0.0361 \\
\hline NHPD33 & 6 & 6 & 1 & 3 & 2 & 2 & 6 & 4 & 0.2978 \\
\hline NHPD42 & 4 & 4 & $1 / 3$ & 1 & $1 / 2$ & $1 / 2$ & 4 & 2 & 0.1247 \\
\hline HPD11 & 5 & 5 & $1 / 2$ & 2 & 1 & 1 & 5 & 3 & 0.1933 \\
\hline HPD23 & 5 & 5 & $1 / 2$ & 2 & 1 & 1 & 5 & 3 & 0.1933 \\
\hline HPD32 & 1 & 1 & $1 / 6$ & $1 / 4$ & $1 / 5$ & $1 / 5$ & 1 & $1 / 3$ & 0.0361 \\
\hline HPD42 & 3 & 3 & $1 / 4$ & $1 / 2$ & $1 / 3$ & $1 / 3$ & 3 & 1 & 0.0827 \\
\hline
\end{tabular}


Table A13. Judgment matrix $\mathrm{Cr}_{26}$ adaptability (final decision).

\begin{tabular}{|c|c|c|c|c|c|c|c|c|c|}
\hline $\mathrm{Cr}_{26}$ & NHPD11 & NHPD22 & NHPD33 & NHPD42 & HPD11 & HPD23 & HPD32 & HPD42 & $\begin{array}{c}\text { Priority } \\
\text { Vector }\end{array}$ \\
\hline NHPD11 & 1 & 1 & $1 / 5$ & $1 / 2$ & 2 & $1 / 4$ & 2 & 1 & 0.0689 \\
\hline NHPD22 & 1 & 1 & $1 / 5$ & $1 / 2$ & 2 & $1 / 4$ & 2 & 1 & 0.0689 \\
\hline NHPD33 & 5 & 5 & 1 & 4 & 6 & 2 & 6 & 5 & 0.3486 \\
\hline NHPD42 & 2 & 2 & $1 / 4$ & 1 & 3 & $1 / 3$ & 3 & 2 & 0.1162 \\
\hline HPD11 & $1 / 2$ & $1 / 2$ & $1 / 6$ & $1 / 3$ & 1 & $1 / 5$ & 1 & $1 / 2$ & 0.0408 \\
\hline HPD23 & 4 & 4 & $1 / 2$ & 3 & 5 & 1 & 5 & 4 & 0.2469 \\
\hline HPD32 & $1 / 2$ & $1 / 2$ & $1 / 6$ & $1 / 3$ & 1 & $1 / 5$ & 1 & $1 / 2$ & 0.0408 \\
\hline HPD42 & 1 & 1 & $1 / 5$ & $1 / 2$ & 2 & $1 / 4$ & 2 & 1 & 0.0689 \\
\hline
\end{tabular}

Table A14. Judgment matrix $\mathrm{Cr}_{27}$ geometry constrains (final decision).

\begin{tabular}{|c|c|c|c|c|c|c|c|c|c|}
\hline $\mathrm{Cr}_{27}$ & NHPD11 & NHPD22 & NHPD33 & NHPD42 & HPD11 & HPD23 & HPD32 & HPD42 & $\begin{array}{c}\text { Priority } \\
\text { Vector }\end{array}$ \\
\hline NHPD11 & 1 & 1 & $1 / 6$ & $1 / 2$ & 1 & $1 / 6$ & 1 & $1 / 2$ & 0.0469 \\
\hline NHPD22 & 1 & 1 & $1 / 6$ & $1 / 2$ & 1 & $1 / 6$ & 1 & $1 / 2$ & 0.0469 \\
\hline NHPD33 & 6 & 6 & 1 & 5 & 6 & 1 & 6 & 5 & 0.3229 \\
\hline NHPD42 & 2 & 2 & $1 / 5$ & 1 & 2 & $1 / 5$ & 2 & 1 & 0.0832 \\
\hline HPD11 & 1 & 1 & $1 / 6$ & $1 / 2$ & 1 & $1 / 6$ & 1 & $1 / 2$ & 0.0469 \\
\hline HPD23 & 6 & 6 & 1 & 5 & 6 & 1 & 6 & 5 & 0.3229 \\
\hline HPD32 & 1 & 1 & $1 / 6$ & $1 / 2$ & 1 & $1 / 6$ & 1 & $1 / 2$ & 0.0469 \\
\hline HPD42 & 2 & 2 & $1 / 5$ & 1 & 2 & $1 / 5$ & 2 & 1 & 0.0832 \\
\hline
\end{tabular}

Table A15. Judgment matrix $\mathrm{Cr}_{28}$ standalonability (final decision).

\begin{tabular}{|c|c|c|c|c|c|c|c|c|c|}
\hline $\mathrm{Cr}_{28}$ & NHPD11 & NHPD22 & NHPD33 & NHPD42 & HPD11 & HPD23 & HPD32 & HPD42 & $\begin{array}{c}\text { Priority } \\
\text { Vector }\end{array}$ \\
\hline NHPD11 & 1 & 1 & $1 / 7$ & $1 / 7$ & 1 & $1 / 7$ & 1 & $1 / 7$ & 0.0312 \\
\hline NHPD22 & 1 & 1 & $1 / 7$ & $1 / 7$ & 1 & $1 / 7$ & 1 & $1 / 7$ & 0.0313 \\
\hline NHPD33 & 7 & 7 & 1 & 1 & 7 & 1 & 7 & 1 & 0.2188 \\
\hline NHPD42 & 7 & 7 & 1 & 1 & 7 & 1 & 7 & 1 & 0.2188 \\
\hline HPD11 & 1 & 1 & $1 / 7$ & $1 / 7$ & 1 & $1 / 7$ & 1 & $1 / 7$ & 0.0312 \\
\hline HPD23 & 7 & 7 & 1 & 1 & 7 & 1 & 7 & 1 & 0.2188 \\
\hline HPD32 & 1 & 1 & $1 / 7$ & $1 / 7$ & 1 & $1 / 7$ & 1 & $1 / 7$ & 0.0312 \\
\hline HPD42 & 7 & 7 & 1 & 1 & 7 & 1 & 7 & 1 & 0.2188 \\
\hline \multicolumn{10}{|c|}{$\lambda_{\max }=8, n=8, C R=0<1$ table consistent } \\
\hline
\end{tabular}

\section{References}

1. Cai, W.; Lai, K.-H.; Liu, C.; Wei, F.; Ma, M.; Jia, S.; Jiang, Z.; Lv, L. Promoting sustainability of manufacturing industry through the lean energy-saving and emission-reduction strategy. Sci. Total Environ. 2019, 665, 23-32. [CrossRef] [PubMed]

2. Fu, Y.; Wang, L.; Li, L. Conceptual design scheme automatic generation and decision-making considering green demand. Procedia Manuf. 2020, 43, 407-414. [CrossRef] 
3. Liu, Z.; Zhao, D.; Wang, P.; Yan, M.; Yang, C.; Chen, Z.; Lu, J.; Lu, Z. Additive manufacturing of metals: Microstructure evolution and multistage control. J. Mater. Sci. Technol. 2021, 100, 224-236. [CrossRef]

4. Gorsse, S.; Hutchinson, C.; Gouné, M.; Banerjee, R. Additive manufacturing of metals: A brief review of the characteristic microstructures and properties of steels, Ti-6Al-4V and high-entropy alloys. Sci. Technol. Adv. Mater. 2017, 18, 584-610. [CrossRef]

5. Bajaj, P.; Hariharan, A.; Kini, A.; Kürnsteiner, P.; Raabe, D.; Jägle, E.A. Steels in additive manufacturing: A review of their microstructure and properties. Mater. Sci. Eng. A 2020, 772, 138633. [CrossRef]

6. DebRoy, T.; Wei, H.L.; Zuback, J.S.; Mukherjee, T.; Elmer, J.W.; Milewski, J.O.; Beese, A.M.; Wilson-Heid, A.; De, A.; Zhang, W Additive manufacturing of metallic components-Process, structure and properties. Prog. Mater. Sci. 2018, 92, 112-224. [CrossRef]

7. Dilberoglu, U.M.; Gharehpapagh, B.; Yaman, U.; Dolen, M. The role of additive manufacturing in the era of industry 4.0. Procedia Manuf. 2017, 11, 545-554. [CrossRef]

8. Wohlers, T.; Campbell, R.; Diegel, O.; Kowen, J.; Huff, R.; Mostow, N. Wohlers Report 2021: Additive Manufacturing and 3D Printing State of the Industry; Wohlers Associates: Fort Collins, CO, USA, 2021.

9. Karapatis, P. A Sub-Process Approach of Selective Laser Sintering; EPFL: Lausanne, Switzerland, 2002. [CrossRef]

10. Kolosov, S.; Vansteenkiste, G.; Boudeau, N.; Gelin, J.C.; Boillat, E. Homogeneity aspects in selective laser sintering (SLS). J. Mater. Process. Technol. 2006, 177, 348-351. [CrossRef]

11. Richardson, J.F.; Harker, J.H.; Backhurst, J.R. Chemical Engineering: Particle Technology and Separation Processes, 5th ed.; Elsevier: Amsterdam, The Netherlands, 2013; Volume 2, pp. 1-1156. [CrossRef]

12. Matel, G.; Claussen, N.; Hausner, H.H. Influence of Relative Humidity on Flow of Metal and Ceramic Powders. In Modern Developments in Powder Metallurgy; Springer: Boston, MA, USA, 1974.

13. Kamalakkannan, S.; Kulatunga, A.K. Optimization of eco-design decisions using a parametric life cycle assessment. Sustain. Prod. Consum. 2021, 27, 1297-1316. [CrossRef]

14. Erenay, B.; Suer, G.A.; Huang, J.; Maddisetty, S. Comparison of layered cellular manufacturing system design approaches. Comput. Ind. Eng. 2015, 85, 346-358. [CrossRef]

15. Mourtzis, D.; Doukas, M.; Psarommatis, F. Manufacturing network design for mass customisation using a genetic algorithm and an intelligent search method. Procedia CIRP 2013, 7, 37-42. [CrossRef]

16. Mourtzis, D.; Doukas, M.; Psarommatis, F. Design and operation of manufacturing networks for mass customization. J. Manuf. Syst. 2015, 36, 274-286. [CrossRef]

17. Psarommatis, F.; May, G.; Dreyfus, P.-A.; Kiritsis, D. Zero defect manufacturing: State-of-the-art review, shortcomings and future directions in research. Int. J. Prod. Res. 2020, 58, 1-17. [CrossRef]

18. Psarommatis, F.; Sousa, J.; Mendonça, P.; Kiritsis, D.; Mendonça, J.P. Zero-defect manufacturing the approach for higher manufacturing sustainability in the era of industry 4.0: A position paper. Int. J. Prod. Res. 2021, 1-19. [CrossRef]

19. Psarommatis, F. A generic methodology and a digital twin for zero defect manufacturing (ZDM) performance mapping towards design for ZDM. J. Manuf. Syst. 2021, 59, 507-521. [CrossRef]

20. Yao, L.; Zou, Z. A one-dimensional design methodology for supercritical carbon dioxide Brayton cycles: Integration of cycle conceptual design and components preliminary design. Appl. Energy 2020, 276, 115354. [CrossRef]

21. Soufi, Z.; David, P.; Yahouni, Z. A methodology for the selection of Material Handling Equipment in manufacturing systems IFAC-PapersOnLine 2021, 54, 122-127. [CrossRef]

22. Napoleone, A.; Brunoe, T.D.; Andersen, A.-L.; Nielsen, K. A tool for the comparison of concept designs of reconfigurable manufacturing systems. Procedia CIRP 2021, 104, 1125-1130. [CrossRef]

23. Van der Schueren, B.; Kruth, J.P. Powder deposition in selective metal powder sintering. Rapid Prototyp. J. 1995, 1, 23-31. [CrossRef]

24. Brackpool, J.L. The effect of material characteristics on the compaction behaviour of metal powders. In Modern Developments in Powder Metallurgy; Springer: Berlin/Heidelberg, Germany, 1971; pp. 423-435. [CrossRef]

25. Soe, S.P. Quantitative analysis on SLS part curling using EOS P700 machine. J. Mater. Process. Technol. 2012, 212, 2433-2442. [CrossRef]

26. Budding, A.; Vaneker, T.H.J. New strategies for powder compaction in powder-based rapid prototyping techniques. Procedia CIRP 2013, 6, 527-532. [CrossRef]

27. Feng, P.; Meng, X.; Chen, J.F.; Ye, L. Mechanical properties of structures 3D printed with cementitious powders. Constr. Build. Mater. 2015, 93, 486-497. [CrossRef]

28. Peyre, P.; Rouchausse, Y.; Defauchy, D.; Regnier, G.; Régnier, G. Experimental and numerical analysis of the selective laser sintering (SLS) of PA12 and PEKK semi-crystalline polymers. J. Mater. Process. Technol. 2015, 225, 326-336. [CrossRef]

29. Drummer, D.; Drexler, M.; Kühnlein, F. Effects on the density distribution of SLS-parts. Phys. Procedia 2012, 39, 500-508. [CrossRef]

30. Bailey, A.G. The science and technology of electrostatic powder spraying, transport and coating. J. Electrost. 1998, 45, 85-120. [CrossRef]

31. Kadonaga, M.; Katoh, T.; Takahashi, T. A study of non-uniform charging by charging roller with DC voltage. J. Imaging Sci. Technol. 1999, 43, 274-279.

32. Kumar, A.V.; Zhang, H. Electrophotographic powder deposition for freeform fabrication. In Proceedings of the 10th Solid Freeform Fabrication Symposium (SFF), Austin, TX, USA, 9-11 August 1999. 
33. Stichel, T.; Brachmann, C.; Raths, M.; Dechet, M.; Schmidt, J.; Peukert, W.; Frick, T.; Roth, S. Electrophotographic multilayer powder pattern deposition for additive manufacturing. JOM 2019, 72, 1366-1375. [CrossRef]

34. Nowak, E.R.; Knight, J.B.; Ben-Naim, E.; Jaeger, H.M.; Nagel, S.R. Density fluctuations in vibrated granular materials. Phys. Rev. E 1998, 57, 1971-1982. [CrossRef]

35. Yang, S.; Evans, J. Metering and dispensing of powder; the quest for new solid freeforming techniques. Powder Technol. 2007, 178, 56-72. [CrossRef]

36. Barker, G.; Mehta, A. Transient phenomena, self-diffusion, and orientational effects in vibrated powders. Phys. Rev. E 1993, 47, 184-188. [CrossRef] [PubMed]

37. Saker, A.; Cares-Pacheco, M.-G.; Marchal, P.; Falk, V. Powders flowability assessment in granular compaction: What about the consistency of Hausner ratio? Powder Technol. 2019, 354, 52-63. [CrossRef]

38. Staffa, K.H.; Jahn, J.; Claussen, N. Flowability of powders under the influence of vibrations. Powder Metall. 1977, 9, 20-23.

39. Matsusaka, S.; Yamamoto, K.; Masuda, H. Micro-feeding of a fine powder using a vibrating capillary tube. Adv. Powder Technol. 1996, 7, 141-151. [CrossRef]

40. Xue, J.; Schiano, S.; Zhong, W.; Chen, L.; Wu, C.Y. Determination of the flow/no-flow transition from a flat bottom hopper. Powder Technol. 2019, 358, 55-61. [CrossRef]

41. Engisch, W.E.; Muzzio, F.J. Method for characterization of loss-in-weight feeder equipment. Powder Technol. 2012, $228,395-403$. [CrossRef]

42. Imole, O.I.; Krijgsman, D.; Weinhart, T.; Magnanimo, V.; Montes, B.E.C.; Ramaioli, M.; Luding, S. Experiments and discrete element simulation of the dosing of cohesive powders in a simplified geometry. Powder Technol. 2016, 287, 108-120. [CrossRef]

43. Matsusaka, S.; Urakawa, M.; Masuda, H. Micro-feeding of fine powders using a capillary tube with ultrasonic vibration. Adv. Powder Technol. 1995, 6, 283-293. [CrossRef]

44. Zhou, C.; Wang, J.; Guo, C.; Zhao, C.; Jiang, G.; Dong, T.; Jiang, F. Numerical study of the ultrasonic impact on additive manufactured parts. Int. J. Mech. Sci. 2021, 197, 106334. [CrossRef]

45. Gorunov, A.I. Additive manufacturing of Ti6Al4V parts using ultrasonic assisted direct energy deposition. J. Manuf. Process. 2020, 59, 545-556. [CrossRef]

46. Wei, C.; Gu, H.; Zhang, X.; Chueh, Y.H.; Li, L. Hybrid ultrasonic and mini-motor vibration-induced irregularly shaped powder delivery for multiple materials additive manufacturing. Addit. Manuf. 2020, 33, 101138. [CrossRef]

47. Yang, Y.; Li, X. Experimental and analytical study of ultrasoAnic micro powder feeding. J. Phys. D Appl. Phys. 2003, 36, 1349-1354. [CrossRef]

48. Yang, S.; Evans, J.R.G. Flow rate of metal powders at reduced and elevated air pressure. Powder Technol. 2005, 154, 95-98. [CrossRef]

49. $\mathrm{Wu}, \mathrm{Y}$;; Du, J.; Choy, K.L.; Hench, L.L. Fabrication of titanium dioxide ceramics by laser sintering green layers prepared via aerosol assisted spray deposition. Mater. Sci. Eng. A 2007, 454, 148-155. [CrossRef]

50. Zhang, K.; Liu, W.; Shang, X. Research on the processing experiments of laser metal deposition shaping. Opt. Laser Technol. 2007, 39, 549-557. [CrossRef]

51. Wang, Z.; Zhang, A.; Shang, X. 3-D design and numerical simulation of two-phase flow in the laser rapid prototyping coaxial powder delivery system. Tsinghua Sci. Technol. 2009, 14, 200-205. [CrossRef]

52. Psarommatis, F. Development of a Powder Management Mechanism for an SLS Machine. Master's Thesis, National Technical University of Athens, Athens, Greece, 2016. [CrossRef]

53. Saaty, R.W. The analytic hierarchy process-What it is and how it is used. Math. Model. 1987, 9, 161-176. [CrossRef]

54. Psarommatis, F.; Zheng, X.; Kiritsis, D. A two-layer criteria evaluation approach for re-scheduling efficiently semi-automated assembly lines with high number of rush orders. Procedia CIRP 2021, 97, 172-177. [CrossRef]

55. Saaty, T.L. A scaling method for priorities in hierarchical structures. J. Math. Psychol. 1977, 15, 234-281. [CrossRef]

56. Pasalopoulos, S.; Avrampos, P.; Vosniakos, G.-C. Surface quality evaluation of non-sintered powder layers in selective laser sintering by 3D scanning. Procedia Manuf. 2020, 51, 748-754. [CrossRef] 